University of St. Thomas, Minnesota

UST Research Online

Operations and Supply Chain Management

Faculty Publications

Operations and Supply Chain Management

2012

\title{
RFID in Healthcare: A Six Sigma DMAIC and Simulation Case Study
}

Peter Southard

University of St.Thomas, Minnesota, sout8188@stthomas.edu

Chandra Cheru

University of Michigan - Ann Arbor

Sameer Kumar

University of St. Thomas, Minnesota, skumar@sthomas.edu

Follow this and additional works at: https://ir.stthomas.edu/ocbopmtpub

Part of the Business Administration, Management, and Operations Commons, and the Management Sciences and Quantitative Methods Commons

This Article is brought to you for free and open access by the Operations and Supply Chain Management at UST Research Online. It has been accepted for inclusion in Operations and Supply Chain Management Faculty Publications by an authorized administrator of UST Research Online. For more information, please contact asle4660@stthomas.edu. 


\section{Article Title Page}

\section{RFID in Healthcare: A Six Sigma DMAIC and Simulation Case Study}

\section{Author Details}

Peter B. Southard

Opus College of Business, University of St. Thomas, St. Paul, MN, USA

Charu Chandra

Department of Management Studies, University of Michigan, Dearborn, MI, USA

Sameer Kumar

Opus College of Business, University of St. Thomas, Minneapolis, MN, USA

Corresponding author: Sameer Kumar

Corresponding Author's Email: skumar@stthomas.edu

\section{Structured Abstract}

\section{Purpose:}

Develop a business model to generate quantitative evidence of the benefits of implementing Radio Frequency Identification (RFID) technology limiting the scope to outpatient surgical processes in hospitals.

\section{Design/Methodology/Approach:}

The study primarily uses the Define, Measure, Analyze, Improve, and Control (DMAIC) approach and draws on various analytical tools such as work flow diagrams, value stream mapping, and discrete event simulation to examine the effect of implementing RFID technology on improving effectiveness (quality and timeliness) and efficiency (cost reduction) of outpatient surgical processes.

\section{Findings:}

Analysis showed significant estimated annual cost and time savings in carrying out patients' surgical procedures with RFID technology implementation for the outpatient surgery processes in a hospital. This is largely due to elimination of both the non-value added activities of locating supplies and equipment and also the elimination of the "return" loop created by preventable post operative infections. Several poka-yokes developed using RFID technology were identified to eliminate those two issues, as well as, for improving the safety of the patient and cost effectiveness of the operation to ensure the success of the outpatient surgical process.

\section{Practical implications:}

Several poka-yokes developed using RFID technology were identified for improving the safety of the patient and cost effectiveness of the operation to ensure the success of the outpatient surgical process.

\section{Originality/value:}

Many stakeholders in the hospital environment will be impacted including patients, physicians, nurses, technicians, administrators and other hospital personnel. Different levels of training of hospital personnel will be required, based on the degree of interaction with the RFID system. Computations of costs and savings will help decision makers understand the benefits and implications of the technology in the hospital environment.

Keywords: Business Process Re-engineering/Patient Focused Care, Six Sigma, Continuous Quality Improvement, Patient safety, PDCA

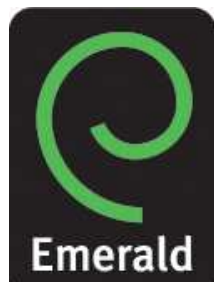




\section{Article Classification: Case study}

For internal production use only

\section{Running Heads:}

Type footer information here

(c) Emerald Group Publishing Limited

This is a pre-print of a paper and is subject to change before publication. This pre-print is made available with the understanding that it will not be reproduced or stored in a retrieval system without the permission of Emerald Group Publishing Limited. 


\title{
RFID in Healthcare: A Six Sigma DMAIC and Simulation Case Study
}

\begin{abstract}
Objectives: Develop a business model to generate quantitative evidence of the benefits of implementing Radio Frequency Identification (RFID) technology limiting the scope to outpatient surgical processes in hospitals.
\end{abstract}

Methods: The study primarily uses the Define, Measure, Analyze, Improve, and Control (DMAIC) approach and draws on various analytical tools such as work flow diagrams, value stream mapping, and discrete event simulation to examine the effect of implementing RFID technology on improving effectiveness (quality and timeliness) and efficiency (cost reduction) of outpatient surgical processes. Results: Analysis showed significant estimated annual cost and time savings in carrying out patients' surgical procedures with RFID technology implementation for the outpatient surgery processes in a hospital. This is largely due to elimination of both the non-value added activities of locating supplies and equipment and also the elimination of the "return" loop created by preventable post operative infections. Several poka-yokes developed using RFID technology were identified to eliminate those two issues, as well as, for improving the safety of the patient and cost effectiveness of the operation to ensure the success of the outpatient surgical process.

Conclusions: Many stakeholders in the hospital environment will be impacted including patients, physicians, nurses, technicians, administrators and other hospital personnel. Different levels of training of hospital personnel will be required, based on the degree of interaction with the RFID system.

Computations of costs and savings will help decision makers understand the benefits and implications of the technology in the hospital environment.

Keywords: Radio Frequency Identification, Simulation, Healthcare Supply Chain Management, DMAIC, Poka-yoke.

Type of Paper: Case Study 


\section{INTRODUCTION}

Increasing competition and artificially-imposed price controls in healthcare are forcing caregivers to rethink how they manage their delivery systems. Healthcare delivery systems must be able to provide extremely high-quality care at reasonable costs. Variation in the systems and processes needed to deliver the healthcare 'product' increases the costs and reduces the quality of that healthcare. It does so, partly, by increasing the time needed to deliver the service. Those three issues; enhancing quality, improving timeliness, and reducing cost, are often intertwined with another major area of concern, that of hospital medical errors (Kumar and Steinebach, 2006). One of the primary goals of healthcare must be, then to identify and reduce the root causes of variation in its processes and systems.

Business organizations have often utilized Six Sigma methodologies and tools in order to accomplish that goal. This study looks at applying the primary methodology of Six Sigma; the Define, Measure, Analyze, Improve, and Control (DMAIC) cycle, developed by General Electric, to reduce the variability inhibiting those goals. The DMAIC methodology evolved from W. Edwards Deming's version of the Plan, Do, Check, Act (PDCA) cycle (also known as the Shewhart Wheel after its inventor, Walter Shewhart). Six Sigma, and the DMAIC methodology imbedded within it, is widely used in business and its application in a business setting is described by Kumar and Sosnoski (2009). DMAIC is often described as "a simple performance model" where:

$\mathrm{D}=$ Define the goals of the improvement activity

$\mathrm{M}=$ Measure the existing system

$\mathrm{A}=$ Analyze the system to identify ways to eliminate the gap between the current performance of the system and the desired goal

$\mathrm{I}=$ Improve the system

$\mathrm{C}=$ Control the system

This study also used the process improvement tool of discrete event simulation to examine the effect of radio frequency identification (RFID) technology on improving the two primary concepts of service delivery: effectiveness (which consists of quality and timeliness) and efficiency (which incorporates cost reduction). Specifically, in applying the DMAIC methodology, this study developed a discrete event simulation of a typical healthcare process, using data from literature and an actual hospital 
to develop the parameters, as part of the Analyze step. Then, as part of the Improve step, it created a hypothetical process where radio frequency identification (RFID) was used to track and coordinate the resources needed to produce the services of a healthcare system. The study then compared the two.

RFID has now been in use in various applications for over half a century and general details of the technology are explained in the next section. Its 'forced' implementation by the suppliers of both WalMart and the United States Department of Defense (DOD) has become a business success story. Many of RFID's benefits and costs, however, are still the subject of debate and additional research in these areas are still needed. This is also true of RFID's applications in the field of healthcare. Its implementation in several healthcare systems in the U.S. and overseas has produced much anecdotal evidence and some quantitative evidence as to its benefits. One purpose of this paper is to produce additional quantitative evidence of the benefits of implementing RFID in healthcare processes. The other purpose is to answer the business research question of whether the implementation of RFID improves the effectiveness (improves quality and timeliness) and efficiency (lowers costs) of delivering services in healthcare systems. Due to the overall complexity of the healthcare industry, this study limited its scope to a particular process within the industry; that of regular scheduled hospital outpatient surgery. Although this process presents a somewhat limited chain of tasks, these tasks do represent a relatively typical healthcare delivery process.

The rest of the paper is organized as follows: A discussion of related work is carried out next. Then, a discussion of the analytical framework used to analyze the research question is offered.

Following this, major findings of the study, its managerial implications, limitations, and conclusions and recommendations are provided.

\section{BACKGROUND}

The following literature review highlights some key studies that offer a picture of the current medical needs of the U.S. population and the opportunity that RFID technology presents to improve the U.S. healthcare system. 


\section{The Medical Need for Improvement}

Competition, politics, and the realities of global epidemics have combined to place healthcare, its costs, and its delivery capabilities, at the forefront of current topics. The entire issue of a recent leading operations management journal, Decision Sciences, was dedicated to those concerns. In that journal, the Editor noted that the complexities and diversities present in the healthcare supply chain may require unique approaches, methodologies and tools (Smith-Daniels, 2009).

Like any other business, the delivery of healthcare services suffers from operational problems. Fredendall, et.al. (2009) found a significant number of delays, an indicator of process variation, in the start of operating room procedures due to simple things, such as instruments, equipment and supplies not being available or what was termed an operational failure because the nurse had to leave the room to find the proper supplies. Correa et al. (2007) stated that, in one situation, nurses were spending an average of 15 to 20 minutes per shift trying to locate the proper equipment. Tu et al. (2009) reiterated the point, writing that the average hospital cannot locate nearly $15 \%$ to $20 \%$ of its assets at any one time. According to Davis (2004), U.S. hospitals waste as much as $\$ 50,000$ per month in unnecessary equipment rentals due to misplaced or lost equipment. Britton (2007) noted that finding 'lost' medical equipment just for scheduled maintenance was costing one facility upwards of 250 labor-hours per year at an annual monetary loss of $\$ 20,000$. That same hospital estimated that over $20 \%$ of its equipment missed routine maintenance for the same reason. Identifying open beds is critical to capacity, yet Kannry, et.al. (2007) found that one hospital lagged almost three hours in showing a bed was open and available. Time spent looking for items, whether equipment or space, is both non-value added and a contributor to process variation.

Medical errors cost both lives (44,000 to 98,000 per year) and money ( $\$ 2$ billion per year to hospitalized patients) (Chao et. al, 2007). Mayo Clinic's Gastroenterology and Colorectal Surgery section was reporting error rates of over 7\% in its pathology labs due to mislabeling and other causes (Francis et. al, 2009). These studies indicate that there is a clear lack of operational coordination required to make sure that the right people are in the right place at the right time with all of the right equipment. In other 
words, managers of healthcare systems need to reduce variation in the system's ability to bring patient, staff, equipment and supplies together.

The Six Sigma framework has been utilized in a number of cases in the Healthcare environment: improving both patient care and business processes and outcomes at the Mt. Sinai Medical Center (Chassin, 2008), reduction of medication errors at the Alton Memorial hospital, Illinois (Benitez et al., 2007), integrate information and enterprise-wide healthcare delivery system issues within an inpatient retail pharmacy operation in a U.S. community hospital (Kumar and Kwong, 2011) and analysis of pharmaceutical supply chain using the DMAIC process for improvement of the reverse logistics in a recall to avert the possibility of harm to a consumer (Kumar, Dieveney and Dieveney, 2009). Implementing the Six Sigma system has led to greater efficiency and reduced delays in hospitals in California and elsewhere (Pexton, 2005). Borkowski and Gordon (2006) advocate that Six Sigma methodologies work just as well in the healthcare industry, as in manufacturing to help reduce the variation in clinical and business processes that cause poor outcomes and high costs. Kumar and McKewan (2011) leverage application of Six Sigma DMAIC cycle in examining the expanded role of nurses in the U.S. for delivering improved healthcare during and post-hospitalization of patients. In another study, Kumar and Sosinski (2009) utilize Six Sigma quality approach to determine current state of service delivery from the perspective of parents or guardians within the U.S. and propose solutions to minimize errors in diagnosis and treatment of childhood strokes. Lanham and Maxson-Cooper (2003) describe the experience of an healthcare organization in successfully reducing medical errors and thereby enhancing patient safety by utilizing techniques based on the six sigma concepts. A comprehensive review of six sigma applications in healthcare industry by Taner et al. (2007) reveals that these have improved the overall operations of the healthcare organization utilizing them.

\section{Radio Frequency Identification (RFID)}

RFID is a relatively simple technology that consists of a tag, a reader, and a software program that integrates the RFID equipment and the organization's computer system. The tag is relatively small and incorporates a tiny receiver, transmitter and antennae and comes in two types; active and passive. 
Passive tags are powered by energy sent out by the reader while active tags contain their own miniature battery. The anti-theft tags found in media, such as DVDs, electronics and other consumer goods are examples of RFID technology as is the Easy-Pass system in interstate toll systems. Much industry literature has been published touting the benefits of RFID in healthcare applications. Currently, RFID technology is widely available and relatively easy to integrate into the healthcare supply chain (Angeles, 2005, Chopra and Sodhi, 2007, Davis, 2004, Fanberg, 2004). Some academic literature has been produced arising from the implementation of RFID systems in a series of hospitals in Taiwan and the probable requirement for drug tracking systems being mandated by the U.S. Department of Defense, the Department of Health and Human Services and the Food and Drug Administration (FDA). The Taiwanese implementation was the result of a Taiwanese government response to the Severe Acute Respiratory Syndrome (SARS) epidemic of 2003 (for description of project, see Tzeng, et.al. (2008)). In one of those studies, Chao, et.al. (2007), studied how RFID could help improve patient safety by reducing medical errors through technological systems that they identified as: medication safety information systems, high risk reminder systems, surgical patient safety systems, adverse events reporting systems, and emergency room RFID systems. Lin, et.al. (2008), detailed how RFID has already been implemented to track dementia patients. In their paper, patients wore RFID chips in necklaces and the facility had RFID readers installed in doorways to alert caregivers, if patients were not where they were supposed to be.

Much of what has been published merely assesses possible uses of RFID (Dinh, 2008, Sun et al, 2008, Martini, 2008, Lavine, 2008, Fisher and Monahan, 2008, Kumar et al, 2010, Thompson, 2004). This was also the finding of Kumar, et. al. (2009) who illustrated the use of RFID in the childbirth delivery process. In another study, Correa, et.al. (2007) examined potential RFID applications from the perspective of attacking the seven forms of "muda" (a Japanese term for waste) as described in the lean production literature.

\section{ANALYTICAL FRAMEWORK}

This study examined whether Six Sigma's DMAIC cycle could reduce variation in the delivery of healthcare outpatient services, thereby, improving its efficiency and effectiveness. It made use of several 
tools, in successive steps, to accomplish this including discrete event computer simulation. The computer simulation package, Arena, was used to model two systems; the typical existing process and then a process with RFID technology implemented. The main dependent variable was the overall throughput time. Arrival times and processing times for each individual process were obtained either through publicly published sources or through personal interviews with managers and staff from local hospitals.

DMAIC, with its associated tool of simulation, was chosen over alternatives methodologies such as Markov, decision trees, data envelopment analysis or stochastic frontier regression because the study was looking to examine an entire set of tasks that formed a very complex process. It was felt, given the complex interrelationships between tasks and the stochastic nature of those tasks, that simulation was a better tool and has proved successful in medical applications (Francis et al, 2009, Angeles 2005, Chopra and Sodhi, 2007).

\section{Define Phase}

The major purpose of the Define phase is to identify characteristics of the system that are critical to quality to the 'customer' (CTQ). The study involved examining the system constituting a regular scheduled hospital outpatient surgery. The objective of this phase was to determine what creates a) errors and b) bottlenecks or restrictions on the availability of people (e.g., doctors, nurses, technical staff, and administrative staff), places (e.g., operating rooms, recovery rooms, x-ray rooms, and hospital beds) and things (e.g., equipment, tools, and supplies) as well as identify the various costs associated with the outpatient surgery process.

The outpatient surgery center that was modeled was based on a major urban hospital in Minnesota which performs a dozen or so different kinds of procedures on approximately 7,800 patients per year. Typical surgeries include: cataract, eyelid, hernia, veins, nerve, podiatry, ACL, shoulders, cosmetic-breast augmentation, liposuction, plastic surgical procedures, and orthopedic hand surgeries. Gross revenues for 2009 were $\$ 50$ million. The outpatient surgery center was supported by 12 doctors (general primary care physicians) for pre-ops, 12 surgeons, 22 nurses and 7 technicians. The facility has 10 operating rooms, 6 exam rooms and 10 recovery beds. 
The research question evaluated was whether implementing RFID can improve effectiveness and efficiency in that process by:

- Improving traceability and visibility of services and the resources required to produce those services

- Improving the coordination of the resources required to produce the services

- Decreasing cycle time of tasks involved in producing the services

- Improving infrastructure and cooperation among and between resources

- Reducing the likelihood of errors within the processes through the use of poka yokes.

- Inspiring confidence of (reduction of the anxiety of ) patients by improving patient safety

- Reducing chances for infection caused by factors that may be reduced through the use of RFID:

- Failure to follow sterilization protocol

- Lack of cleaning/washing

- Deficient operating room procedures

- Reducing total costs of outpatient surgery process stream.

\section{Measure Phase}

The first step of this phase is to determine the metrics by which to measure the existing process. It is only by having data on the performance of the existing system that a model of the improved state can be created and a plan developed to achieve it. The metrics chosen for the study were:

a) Cycle times of individual tasks within the process

b) Overall throughput time of the process

c) Costs of providing the procedures

d) Utilization of the resources

e) Reduction in errors (first time quality)

As part of the measure phase, a current-state value stream map (csVSM), shown in Figure 1, was created to fully describe and define the processes on which the study intended to focus.

[insert Figure 1 about here]

This csVSM analyzed the basic value chain that exists in the hospital system. The map indicated there were significant areas that could be improved, specifically with regard to the need to eliminate the non-value added time that was spent on locating equipment and supplies at various process stages. It also 
identified problems that could arise from complications created by improper procedures and / or sterilization which occurred prior to, during, and between surgeries.

These two areas were specifically targeted for process improvement using RFID technology.

\section{Analyze Phase}

The analyze phase of DMAIC focuses on the causes of variation and errors. It then looks to identify the root cause of those issues. It does this by promoting a thorough knowledge of what the process is, what it currently does, what it should do, what its capabilities are, and how the processes should be controlled. This study used several six sigma tools to accomplish that.

To analyze the variation found in the processes and the effects of implementing RFID within those processes to reduce that variation, the following tools were used; process mapping and a discrete event simulation. Process mapping simply involves diagramming and focusing on the individual tasks needed to transform inputs into a particular output; the service. It is also the bottom half of the value stream map, already discussed. The next step was to analyze and determine how to incorporate RFID in order to improve the system.

\section{RFID Implementation}

The RFID implementation would include several aspects of the technology including the following:

1) Each patient wristband would incorporate a passive RFID chip (passive tags are approximately $\$ .10$ each).

2) Each employee nametag would incorporate a passive RFID chip.

3) All hospital equipment would bear an identification sticker that contained a passive RFID chip. This includes technical medical equipment (crash carts, portable x-ray, monitors) and housekeeping medical equipment (beds, wheelchairs, gurneys). RFID tags that can be sterilized are available.

4) Bulk hospital supplies and drugs can be labeled with active RFID tags (which can maintain a record of environmental temperature, tampering, etc.) while individual containers or packs 
would have passive tags. Active tags (approximately $\$ 50$ each) are reusable and reprogrammable.

5) Separate RFID tag readers will be assumed to be unnecessary as most hospitals are able to use their existing wireless area local networks (WLAN and often referred to as Wi-Fi) to act as RFID readers. Particular areas not covered by an access point (a hotspot) may require a separate reader. For the costs in the table, it was assumed each operating room would need a separate reader.

The approximate costs of this system are broken out in Table 1, Specific RFID Implementation Costs. Costs of the RFID system can vary tremendously based on the equipment, software and infrastructure. Costs for one hospital were as low as $\$ 35,000$ for software and $\$ 50$ for each active RFID tag (interview and correspondence with Chris Wassel, RFID Program Manager of the RFID Center of Excellence, Penn State Erie, The Behrend College, in Erie, PA). That hospital did not need readers as they used an existing internal Wi-Fi structure. Due to the wide-spread use of wide-area wireless networks, this study assumed the same.

One way to look at the operational benefits, and operational assumptions, of that implementation is to describe it in terms of the errors that can occur in the processes (as identified in the current value stream map) and methods of preventing those mistakes from occurring. A term borrowed from business that describes tools and methods implemented to prevent mistakes from occurring is poke-yoke. Pokeyoke is a Japanese term that, when translated into English, means mistake-proofing. It came to prominence as American auto manufacturers began to adopt the 'lean' production techniques made famous by the Toyota Corporation.

In another study, one of the authors identified where various poka-yokes can be strategically applied in a hospital setting (Kumar and Steinebach, 2006). Described below are the possible failures identified in that article and a number of mistake-avoidance measures (poka-yokes) that incorporate RFID, including how these identification tags can be tactically implemented in an outpatient surgery process. 
Failure I: patient mix-up.

Poka-yoke: nationwide patient number. Every patient in the U.S. with a unique nationwide patient number (like a social security number) imbedded in an RFID tag worn on the wristband of the patient, would prevent hospital staff members, as well as pharmacists, from mixing-up patients or patient records. With readers located at strategically situated positions throughout the hospital, along with the location capabilities provided by the existing wireless infrastructure in most hospitals, the patient's identification and exact location are constantly monitored in real-time.

Failure II: patient mix-up (continued).

Poka-yoke: wrist band, including nationwide patient number, name and birth date. When the patient arrives, the administrative person or nurse who works at the front desk of a hospital admits the patient. They should prepare a wristband with an RFID chip that contains the patient's national patient number, birth date, and name along with a synopsis of the patient's medical history and reason for visit. This band is then put on the patient's wrist.

Failure III: patient mix-up (continued). Inaccurate information on patient record/mix-up of patient records.

Poka-yoke: wristband, including national patient number, name and birth date connected to a nationwide online database. The use of a wristband containing an RFID chip alleviates the need to physically scan the patient's wristband each time identification is required. When a patient enters a room, either a specific reader or the wireless infrastructure recognizes the data on the chip and instantaneously brings up the correct patient's information on the computer in that room.

Failure IV: miscommunication between physicians and nurses.

Poka-yoke: diagnosis and notifications must be completed through the online record. Doctors and nurses will be required to complete everything in the online patient record (diagnose, notifications, comments, medications given, medical problems, allergies, etc.). When the patient goes to the next step, if 
he has to be scanned again, then the updated information will appear. As physical scanning is no longer required, this step is significantly simplified, and therefore speeded up with reduced errors, by the use of RFID. The correct patient's file is automatically displayed for updating as soon as the patient enters a new room or area. While not completely eliminating miscommunication, the practice should reduce it.

(Kumar and Bauer, 2009)

Failure V: patient is given the wrong medication or medication dosage.

Poka-yoke: online medication ordering system. To avoid medication errors, ordering the patient's drugs online would be better than ordering the paper prescriptions. To avoid any source of error, a physician would type them into an online form. The system then checks if the prescribed drug exists. Since the medication has already been ordered online for post-operative medications, the hospital would issue a pharmaceutical ID with an RFID tag imbedded in it that would be required for purchase of needed medications. It would be this ID that is read at the participating pharmacy. In addition, under developing mandates from the government, drug containers will have RFID tags as well; though the initial purpose of the mandates requiring these tags is to facilitate documentation of the pedigree of the drug (reducing the infiltration of counterfeit drugs).

Failure VI: knowledge errors/wrong diagnosis/wrong medication/wrong medication dose.

Poka-yoke: continuing obligatory training/education for doctors and nurses. Incorrect diagnosis is capable of triggering not only one, but several medical errors as every succeeding physician or nurse relies on the primary care-doctor's diagnosis. This may occur with lack of familiarity of new methods of surgery and anesthesia by physicians and nurses. Data on physician's and nurse's continuing education would be maintained on a national database. As each hospital employee carries an identification card containing an RFID tag, the attending employee's credentials are recognized when they enter a treatment area. If credentials are not current, a warning is noted on the local computer screen.

Failure VII: lack of experience.

Poka-yoke: training on the job. Data on physician's and nurse's continuing education would be maintained on a national database. As each hospital employee carries an identification card containing an 
RFID tag, the attending employee's credentials are recognized when they enter a treatment area. If credentials are not current, a warning is noted on the local computer screen.

Failure VIII: fatigue.

Poka-yoke: working limit. Medical errors caused by physician or nurse fatigue can be reduced through the implementation of maximum working limits. Shift hours are noted when employees check in at the beginning of their shift. Once again, when shift hours near a maximum, a warning is noted on the screen in their treatment area. Once the maximum number of hours is reached, a different warning is issued when the employees RFID tag is read in a treatment area.

Failure IX: negligence.

Poka-yoke: checklists. Negligence can be reduced through implementing checklists. In hospital areas (i.e. in the operating room) that have high adverse event probabilities, if equipment is RFID tagged, then the trays or carts themselves can indicate what equipment is in place and what equipment is missing, both simplifying and speeding up the process of reconciling lists prior to, during, and following surgery.

In this study, we examined several possible ways to poke-yoke, or prevent errors using RFID technology but focused on two additional areas of failure:

1) inability to locate specific supplies/equipment needed to perform surgery at a specific place and time (as seen in Correa et al (2007), Fredendall, et.al (2009, Tu et al (2009) and Davis (2004) mentioned in related work) and

2) Complications arising from not following procedure and improper sterilization (as mentioned in Kumar and Steinebach (2006), also mentioend above).

Each of these failures lower the effectiveness and efficiency of the system because they increase the variation in the processes, as defined in the Introduction section. It should be noted that only that portion of the non-value added time that can be saved by the use of RFID was considered. As long as humans are involved in the tasks, there will always be errors and complications that RFID cannot eliminate. 
What this study examined was the effect of implementing poka yokes using RFID, particularly those poka yokes relating to reducing the possibility of patient misidentification, missing or lost supplies and equipment, and complications created by fatigue, sterilization issues, or training. The effect of implementing them is modeled through time savings and reduced reentry of patients into the system from postoperative infections. This was accomplished in two stages. First, using data from hospitals and secondary sources a model was created to simulate the process without RFID. Then, using data from secondary sources on the individual improvements in time and costs created by developing each of the separate poka yokes using RFID, a simulation model was created that aggregated those benefits through the system.

RFID would help to poke-yoke these failures in the following ways; locating supplies and equipment is facilitated as the hospitals wireless network system can, in real time, determine the location of any supply or piece of equipment bearing an RFID tag by the unique signal it returns when queried by the system. Its signal is picked up by the wireless system and its location displayed on any computer screen. By reducing the search for either items or space, non-value added time (and the cost associated with that time) is also reduced as is the variation created by the addition of the non-valued added time.

Reduction of complications caused by post-operative infections would take place as the tags on employees would determine whether that employee had been in proximity of sterilization areas (sinks), display the appropriate procedures for a particular patient (after reading the patient's RFID wrist tag) in a particular operating room and require the appropriate employees to electronically sign off that they have read that procedure. The reduction of post-operative infections also reduces variation created by randomly reintroducing patients back into the system.

While implementing RFID is daunting, and is usually done in steps, the proposed system in the study assumes that the technology is being adopted by the hospital system as a whole. It is only in this manner that the full benefits of RFID can be realized.

To determine the outcomes of implementing these poke-yokes, or error-proofing ideas, the study needed to analyze their effect on the current system. Experimenting on an actual system, however, 
without knowing the consequences can cause unneeded disruptions and costs. Simulation provides a way to understand implementation ramifications without disrupting the actual system.

RFID vs. Bar-codes

Many hospitals already use bar-coding for identification purposes. This brings up the question of what are the benefits of incurring the additional expense of implementing RFID? While bar-coding has the advantage of lower cost, it also has two distinct disadvantages.

1) In order to input or read a barcode, an individual must be able to physically see and then scan that visible code with another physical piece of equipment, a reader. This makes its application in locating missing items essentially the same as having no system at all. With RFID, a tag can be scanned by the existing wireless system within the facility (or by a stationary tag reader as the tag passes near to it) with no additional effort by another party.

2) A barcode holds a single piece of information. RFID tags can hold multiple pieces of information and can, in the case of active tags, record information, such as ambient temperature, movement, and tampering that occurs on or within the item tagged.

In the case of the types of errors being studied here, bar-codes would not be able to prevent the failures.

\section{Simulation Model}

The models developed by Kumar, et.al. (2009), and Elbeyli and Krishnan (2000) provided a starting point by which to analyze the systems under study. The first step was to define the tasks in the process. To illustrate this, a basic outpatient surgical process flow map, shown in Figure 2, was created.

[insert Figure 2 about here]

The dependent variables of the model are processing time (throughput time), costs of resources, and resource utilization with the independent variable being the difference in tasks arising from the implementation of RFID (and described earlier). 


\section{Explanation of RFID Model Processes}

Though based on data from hospitals, derived from both secondary sources and interviews, the models are designed to represent a generic hospital outpatient surgery system. It assumes that patients are scheduled for an appointment prior to their hospital procedures (non-emergency). Times for the various tasks within this process are randomly selected by the model from time distributions in order to represent the stochastic nature of such a system. The parameters of the time distributions for the tasks, and the number of resources available for each task were based mainly on literature from documented empirical studies of similar systems. These sources are noted as the model is described below. If not so noted, times were estimated based on interviews with hospital administrators and staff. In reality, of course, all the parameters can vary tremendously from situation to situation. The focus in this study, however, is on the difference in overall time and costs between the scenario without RFID and the scenario with RFID. Since all other times and costs, those not affected by RFID, are held constant between the two scenarios, it is the relative difference between the models that emerges as the crucial measure for analysis.

\section{Base Model without RFID}

The base model begins with arrivals of scheduled patient entities at the hospital every 90 minutes. The total number of arrivals on any given day is based on a triangular distribution of $\mathrm{T} 25,30,45$. This distribution is based on the demographics of the hospital described in the Define phase through interviews with hospital administrators. Law (2007) notes that in the absence of sufficient actual data, as is the case here, a triangular distribution is appropriate for modeling arrival rates and as an alternative to the Poisson normally used. As soon as patients arrive, they are processed through Scheduled Admittance. This process requires a resource called Staff Pack which has a capacity of 5. The process requires an amount of time selected by the model from a triangular distribution with a minimum of 5 minutes, a maximum of 30 and a most likely of 15 (T $5,15,30)$.

Following admittance, each patient entity is assigned certain qualities including a time attribute beginning at zero to track their throughput time within the model. The next process is the outpatient preoperative examination. This process requires the use of four resources, each of which must be present 
in order for the process to proceed; supplies, exam room, doctor and nurse. Total capacity for the supplies resource is infinite. Capacities for the room, doctor, and nurse are 6, 12 and 22 respectively. Time required for this process is based on a triangular distribution with a minimum of 10 minutes, a maximum of 25 and a most likely of $20(\mathrm{~T} 10,20,25)$. At this point, there is a process within the model entitled Find Supply that assumes there is some effort required to locate the necessary supplies to perform the surgical process based on studies discussed in the section on related work. The time required for this process is based on a triangular distribution with a minimum of .5 minutes, a maximum of 15 and a most likely of $5(\mathrm{~T} .5,5,15)$. Any time the resource supplies is required, there is a corresponding Find Supply process that follows the process in which the resource is used.

The next step in the model is a process to represent pre-operative tests which could include such things as blood tests and x-rays. This process requires four resources; supplies, technician set, test room set and lab equipment set. The capacities for the latter three are seven, two, and two respectively. The time needed to perform these tests is based on a triangular distribution with a minimum of 10 minutes, a maximum of 30 and a most likely of 20 minutes (T10, 20, 30). This distribution comes from a study done by Ahmed and Alkhamis (2009). Preceding the tests is a decision point that allows for the possibility that patients do not need any preoperative tests, but it was assumed, for this model, that at least some tests (e.g., blood tests) are always needed prior to surgery.

Once again, there is a "Find Supply" process that accompanies the testing process. This time, it requires the use of the technician resource and takes $\mathrm{T} .5,10,20$ minutes. The next process in the system is to interpret the patients' tests. This requires a doctor pack resource and takes T 10, 20, 25 minutes. Following this is a decision point that asks whether additional tests are required based on the interpretations of the initial tests. The assumption is that additional tests are required in 5\% of the cases. These $5 \%$ are returned to the initial testing stage. The balance of patients move on to the next process; Outpatient Treatment. This process requires six resources; supply, doctor set, nurse set, technician set surgical equipment set, and operating room set. The last two have capacities of five. Time required for the process is based on a triangular distribution with a minimum of 112.6 minutes, a maximum of 118.9 
and a most likely of 115.8 minutes (T 112.6, 115.8, 118.6). These times are based on Marjamaa, et.al. (2009), and Van Berkel and Blake (2007). There is another Find Supply process associated with surgery, requiring a nurse and a technician and using $\mathrm{T} .5,5,15$ minutes.

Following surgery, the patient is moved to a recovery room. Moving requires a nurse and a technician. It takes T 5, 15, 30 minutes of time. Recovery itself requires the resources of supply, nurse, and recovery bed (e.g., a recovery room). It takes $\mathrm{T} 15,30,60$ minutes of time. This process is also associated with a Find Supply process requiring a nurse and T .5, 5, 20 minutes.

There is a decision point here, since one of the main purposes of monitoring recovery is to identify signs of complications. A decision point has been inserted here that asks if there are complications. In 5\% of the cases, complications arise from factors that could be prevented using RFID technology and are associated with improper procedures such as insufficient sterilization during surgery or incorrect dosages and drug procedures. This $5 \%$ is routed back into the system at the preoperative exam process.

The remaining 95\% enter the discharge process. This process requires the resource supplies and staff pack. The time required comes from DeBusk and Rangel (2004) and is a triangular distribution with a minimum of 56 minutes, a maximum of 112 and a most likely of 84 (T 56, 84, 112). Since supplies are required, there is also a Find Supply process using a nurse set and a staff set requiring T .5, 10, 45 minutes. The model completes with throughput times and other data collected in counting modules.

In order to simulate the need to sterilize certain resources in between patients, the Failure module was used so that the resources were unavailable for a short period of time in between patients. Under Advanced Processes, Failures, two types of failures were created, short failures taking a normally distributed time with a mean of 3 minutes and standard deviation of 1 minute and a longer sterilization procedure requiring a mean of 15 minutes with a standard deviation of 5 minutes. Resources using the short sterilization time between patients were doctors, nurses, and technicians. Resources using the longer sterilization time were all the rooms and equipment packs. These processes are summarized in

Table 2. A diagram of the model is shown in Figure 3. 
[insert Table 2 about here]

[insert Figure 3 about here]

For clarification, there are four types of modules used in the model diagram shown in Figure 3. Basic flowchart symbols are used to illustrate various aspects of the model. The main modules are the process modules representing the tasks that require time and resources. These are represented by rectangular shapes. The diamond shapes represent decision points and determine the flow of entities through the model based on true/false statements. Assign modules and record modules are supporting modules that merely assign variable to entities and record the data collected. These stages neither require time nor consume any resources.

\section{Model With RFID}

The model including RFID assumes that the implementation of RFID will significantly improve the coordination and visibility of the processes required to complete an outpatient surgical system. These benefits were seen in somewhat similar situations in the section on Related Work. To represent that coordination and visibility, the additional processes associated with Find Supply have been removed in the 'with RFID' model since all supplies will be tagged with RFID labels and their whereabouts constantly monitored in real time. There should be no additional time needed to locate them.

The decision point located after the recovery process, complications, has been changed to indicate no complications due to post-operative infections created by improper procedures or insufficient sterilization. The remaining processes, times, and resources remain the same as in the base model. A diagram of this model is shown in Figure 4.

[insert Figure 4 about here]

\section{Model Cost Assumptions}

The models incorporate cost assumptions gathered from public sources. Nurses, administrative staff, and technical staff are paid on an hourly basis. Each set of wages was taken from the United States Bureau of Labor Statistics website (www.bls.gov). Wages used were $\$ 34.00 /$ hour, $\$ 15.50 /$ hour and $\$ 22.00 /$ hour respectively. 
Doctors' and Surgeons' costs were based on a per procedure basis (identified as 'per use' in the table). While some hospital physicians are salaried (e.g., the Mayo Clinic in Rochester, MN), these models assume a more traditional form using the per procedure basis. The amount was based on an average of the billed costs of 72 common procedures across the United States as published by the American Medical Association (AMA) in its report located on the U.S. Health and Human Services website (http://www.cms.hhs.gov/HealthCareConInit/04_Physician.asp). This average amount was calculated as $\$ 100$ per procedure ('per use' in the table) for the preliminary examination by a doctor and $\$ 2,071$ per operation procedure ('per use' in the table) for surgeons.

The average total reimbursable cost of an outpatient hospital stay was determined by the United States Office of Management and Budget to be $\$ 6,777.50$ per day according to a report it published on the U.S. Government White House web site (Whitehouse, U.S. 2011).

Subtracting the physician charge from the total daily charge leaves $\$ 4,706.5$ which is assumed to be the amount needed to cover overhead (room charges), equipment needs, and supplies. This amount was therefore equally divided between the following on a per procedure basis: surgical equipment pack, lab equipment pack, exam room, operating room, testing room, recovery room, and supplies. Each of these items was assigned a cost of $\$ 784.42$ per procedure. While the equal allocations may not be accurate in a real-life setting, they should suffice until empirical data can be found or collected. This is due to the fact that since the costs are allocated on a per procedure basis and the number of procedures per day should not vary significantly between the two models, differences in the allocations will not significantly affect the results of the model. The costs associated with each resource are summarized in Table 3.

[insert Table 3 about here]

\section{Other Model Assumptions}

It was assumed that, because of the nature of the process, and based on interviews with hospital personnel, resources needed to be cleaned and sterilized between patients. This was modeled as resource downtime failures. People, such as surgeons, physicians and nurses as well as equipment and rooms were 
all assumed to need sterilization between uses. People used a shortened sterilization period (a normal distribution with mean of 3 minutes and standard deviation of 1 minute) and rooms and equipment a longer period (a normal distribution with mean of 5 minutes and standard deviation of 5 minutes). One of the advantages seen with RFID is that of transparency and the prevention of errors. As described earlier, RFID tags on employee tags, equipment carts and sterilization equipment or locations can help enforce policies and procedures regarding sterilization between patients, reducing the incidents of post-operative infections. In the current models, however, the failure rates and times were kept the same, controlling for this variable and allowing it to be measured in a future study.

Along with the model, a future state values stream map (fsVSM) was developed to indicate the improvements that had occurred due to the elimination of steps facilitated by RFID.

[insert Figure 5 about here]

This fsVSM indicates the value stream created by the implementation of RFID.

\section{Improve Phase}

Pyzdek and Keller (2010) explain that the goal of the Improve phase of DMAIC is to implement the changes to the system that are needed to improve it. In this study, the improve phase consisted of a theoretical implementation of radio frequency identification (RFID) to the processes under study and simulating those processes as if that technology were in place. The improvements were based on the benefits, or amount of progress, noted in prior studies in the section on related work. The breakdown of costs and time savings and also cost benefit analysis are presented below. Pyzdek and Keller also note that the new system should be evaluated for risks so a sensitivity analysis was also conducted.

\section{Breakdown of Costs and Time}

Comparing the two models results in Table 4 which shows total costs as well as the average cost and time per patient with and without the RFID system.

[insert Table 4 about here]

Model Costs were broken down, in terms of entity use, into value-added and non-value added by process. All processes, except moving the patient and searching for supplies, were considered value- 
added. By default, the model considers any waiting time (time used while waiting in queues or waiting for a required resource) as non-value added.

Costs are also broken down by resources based on whether the resource accumulates costs on an hourly basis or on a per-use basis. Table 3, described earlier, lists all resources and how costs were accumulated. Staff, technicians and nurses were paid hourly, while doctors, equipment, facilities and supplies accrued costs on a per use basis. These costs are then reported as busy or idle for the hourly resources. Busy costs are those costs created when the resource is active in a process whether that process is value added or not. Idle costs accrue when that resource is not in use by any process (and is assumed to be in use by other processes not included in this model).

Time per patient was divided into three categories; value added, non-value added, and wait time. Value added time occurred when the patient entity was involved in a process that was designated as value added; the same with non-value added time. Wait time is accumulated when a patient spends time in a queue waiting to enter a process (value or non-value added). These costs and times are summarized in Table 5.

[insert Table 5 about here]

A Future State Value Stream map is shown in Figure 5. As this map indicates, the non-value added activity of locating supplies and equipment has been eliminated. In addition, the loop back created by preventable post-operative infections has also been eliminated since the RFID system creates a pokayoke that insures people, equipment, and facilities are properly sterilized between each patient and procedure.

\section{Control Phase}

The control phase of DMAIC requires that policies and procedures be put in place to maintain the improvements created. The processes must be maintained in the improved state and not be allowed to return to the 'old' way of doing things. Monitoring procedures must be established to be sure the critical metrics remain within acceptable levels. RFID can assist in this control through its ability to gather and 
report information in real time. It also provides immediate visibility into the process, a hallmark of sixsigma and lean processes.

\section{FINDINGS}

Following the DMAIC methodology helped to clarify the process itself and identify issues within the process that were creating both non-value added activities and processes variation. As shown in Figure 5, non-value added activity of locating supplies and equipment will be greatly reduced with the implementation of RFID technology in the outpatient surgical process. The reduction of this activity also reduces the process variation created by the randomness of time spent searching. The "return" loop, created by preventable post operative infections, will be greatly reduced or eliminated since the RFID system creates a poka-yoke that mitigates the potential that people, equipment and facilities are not properly following sterilization protocol between each patient and procedure. This reduction in infection rates contributes to the overall cost savings per week of $\$ 37,163$ with the RFID implementation. This translates into an estimated per patient average cost savings and time savings $=\$ 298$ and 1.1 hours respectively (see Table 4).

The study provided estimates of overall annual cost savings with RFID implementation to be $\$ 1,932,476 \approx \$ 1.93$ million and per patient average cost savings and time savings estimates of $\$ 298$ and 1.1 hours respectively. If, for example, an average of 7,800 patients undergoes outpatient procedures in one year, the surgery center would save 8,580 hours in patient and facility staff time annually.

Analysis of outpatient surgical process value stream using FMEA and simulation of the process allowed for identifying failures and suggesting mechanisms in a system to help prevent such failures. Several poka-yokes using RFID were recommended to avoid patient mix-up, miscommunication between physicians and nurses, inaccurate medication or dose, knowledge errors/wrong diagnosis, fatigue, haste and negligence.

An improved value stream map, with RFID implementation, is developed for outpatient surgical process where non-value-added activities of locating supplies and equipment, as well as complications, in 
recovery are eliminated. The improved value stream process map incorporates suggested poka-yokes. Every decision has a dedicated follow-up to ensure the maximum patient comfort and understanding before the process is allowed to continue.

\section{Sensitivity Analysis}

To fully determine and understand the accuracy of the models, and the benefits tested by them, it is useful to conduct a sensitivity analysis. In this situation, a sensitivity analysis of the input parameters was conducted by examining a worst case and best case scenario in addition to the "average" case scenario already described. To achieve this, sixteen additional models were created. For both scenarios 'without RFID' and 'with RFID', models were created and run that increased all process times by $25 \%$ while holding costs the same, increased all costs $25 \%$ while holding process time the same, increased both costs and process times by twenty five percent, decreased both costs and process times by twenty five percent and, finally, increased each variable while decreasing the other. A summary of the resulting sixteen sets of additional output data are shown in Figures 6 through 17. An analysis of those tables indicates the following:

Total Costs, Total Value-Added Costs, and Average Cost per Patient:

These variables were proportionately sensitive to changes in costs but not to changes in process times. When process time is decreased $25 \%$ and costs increased 25\%, RFID actually loses its cost advantages (see Figures 6,9 and 7).

\section{Average Time per Patient}

This was proportionately sensitive to changes in time but not to changes in costs (see Figure 8). Total Non Value-added Costs (for example, waiting \& queue time)

These variables appeared fairly sensitive to both cost and time changes. Because this variable reflects only queue and waiting time, the sensitivity savings were lower than the base (see Figure 9). 
Total Busy, Idle and Usage Costs

As with Total Costs, all three exhibited the characteristic that as time is decreased $25 \%$ and costs increased 25\%, RFID actually loses its cost advantages. Total Busy Costs appears quite sensitive to both time and cost changes. Idle Costs showed great sensitivity to decreases in process times (see Figure 10).

\section{Per Patient Times}

As expected, Per Patient Times are only sensitive to changes in process times and vary proportionally in the direction of change (see Figures 11 through 17).

\section{MANAGERIAL IMPLICATIONS}

The implications of integrating increased use of RFID technology in hospital operations are enormous and hospital administrators should be closely evaluating the incorporation of this technology. Time, money, effort, and medical errors resulting in patient injuries and deaths could all be greatly reduced with the proper implementation of this technology (Chopra and Sodhi, 2007). Resources could be better leveraged with RFID implementation. Equipment, materials and patients can be more effectively managed to lower overall operational costs. Time to locate materials, equipment, and clinical staff will be greatly reduced. A history of the use of a product or piece of equipment can be kept and potential problems can be isolated much more quickly with proper records as part of RFID technology (Angeles, 2005, Bacheldor, 2009, Chopra and Sodhi, 2007).

\section{LIMITATIONS OF THE STUDY}

This is an industry-specific study and specific to a particular set of processes within one example of that industry. This study was constrained by the limited access to information due to the sensitive nature of medical records/history within the supply chain and availability of only a few basic studies in the professional literature. In addition, only a high-level value stream map was created for the surgical operating process in an outpatient setting. An in-depth map and a pilot study could provide more verification and validation of initial time savings with additional resources. 


\section{CONCLUSIONS}

The study examined whether RFID implementation in the outpatient surgery processes in a hospital can improve traceability and visibility of patient, equipment, healthcare delivery personnel, and supplies, as well as the improvement of the infrastructure, coordination and cooperation required to remove medical errors, reduce chances of infection, inspire confidence of patients through patient safety and decrease the cycle time of tasks associated with patient procedures. Based on the results of the model, it appears that RFID has the capability to do so in a cost effective manner. The contributions of this study lie in the practical applications and everyday uses of RFID technology for healthcare delivery professionals within the healthcare supply chain, namely, physicians, nurses, technicians and hospital administration staff. The study also informs hospital administrators and clinical staff on the current state of RFID technology and the possible and likely applications of this technology in healthcare delivery operations. It is apparent after reviewing current literature and studies on the application of RFID technology that practical managerial steps and information is lacking.

Achieving the operational blueprint with RFID technology fully imbedded in hospital operations will require involvement of clinical staff and it will rely upon cost benefit analysis to support the operational improvement initiatives through significant changes in business processes and workflow with RFID technology solution in various parts of hospital delivery functions. Clinical staff will have valuable input and their participation will facilitate buy-in of the initiatives. Neglecting to involve physicians in the project at the beginning can have strong negative implications. Involving senior hospital leadership in the decision-making process and leveraging RFID technology can make the hospital supply chain a highperforming area. Investing resources into RFID projects can yield significant reductions in operating costs, as well as improved business processes, patient safety and satisfaction, medical services, equipment and material management as described earlier in the paper.

\section{RECOMMENDATIONS FOR FUTURE STUDY}

It may be necessary to more fully study the mindset and attitudes of managers supporting various parts of the healthcare supply chain so that incorporating RFID technology in various healthcare delivery 
processes can be effectively planned. As was shown in this single case study for outpatient surgery center, benefits outweigh costs of implementation of RFID based tracing and tracking system. However, it would be useful to consider where the decision makers that could make the biggest difference are at regarding RFID information. We would like to further explore the following specific issues: Whether hospital management believes in RFID applications and utilization and what is management's perception about the cost of RFID and the return on investment? It may be worthwhile to conduct field study interviews to supplement managers' views from the operating level.

\section{REFERENCES}

Ahmed, M. A. and Alkhamis, T. M. (2009), "Simulation optimization for an emergency department healthcare unit in Kuwait", European Journal of Operational Research, Vol. 198, pp. 936-942.

Angeles, R. (2005), "RFID technologies: supply-chain applications and implementation issues", Information Systems Management, Winter, pp. 51-65.

Bacheldor, B. (2009), "RFID Prevents Valued Hospital Assets from Getting Trashed", RFID Journal, April 21, available at: www.rfidjournal.com/article/view/4808.

Benitez, Y., Forrester, L., Hurst, C. and Turpin, D. (2007), "Hospital reduces medication errors using DMAIC and QFD”, Quality Progress, Vol. 40 No.1, pp. 38-45.

Borkowski, N. and Gordon, J. (2006), "Entrepreneurial organization: The driving force for improving quality in the healthcare industry", Journal of Health \& Human Services Administration, Vol. 28 No. 4, pp. 531-549.

Britton, J. (2007), "An investigation into the feasibility of locating portable medical devices using radio frequency identification devices and technology", Journal of Medical Engineering Technology, Vol. 31, pp. $450-458$.

Chao, C. C., Jen, W.Y., Chi, Y.P. and Lin, B. (2007), "Improving patient safety with RFID and mobile technology," International Journal of Electronic Healthcare, Vol. 3, pp. 175-192.

Chassin, R. (2008), "The six sigma initiative at Mount Sinai Medical Center", Mount Sinai Journal of Medicine, Vol. 75, pp. 45-52.

Chopra, S. and Sodhi, M.S. (2007), "In search of RFID's sweet spot”, The Wall Street Journal, March 34, p. R10.

Correa, F. A., Gil, M.J.A, and Redin, L.B. (2007), "RFID and health management: is it a good tool against sytem inefficiencies," International Journal of Healthcare Technology and Management, Vol. 8, pp. 268-297.

Davis, S. (2004), “Tagging Along - RFID helps hospitals track assets and people”, Health Facilities Management, December, pp. 20-24. 
DeBusk, C. and Rangel, A. (2004), "Creating a Lean Six Sigma Hospital Discharge Process: An iSixSigma Case Study", isixsigma.com, available at:

http://healthcare.isixsigma.com/library/content/c040915a.asp

Dinh, A. K. (2008), "RFID Systems in Healthcare - Emerging Uses and Potential Issues", Journal of AHIMA, Vol. 79 No. 1, pp. 62-63.

Elbeyli, S. and Krishnan, P. (2000), In-Patient Flow Analysis Using Promodel ${ }^{T M}$ Simulation Package, FREC Staff Paper, Vol. SP00-02 November, University of Delaware.

Fanberg, H. (2004) The RFID Revolution - healthcare is ready to embrace this new technology, Marketing Health Services, Fall, pp. 43-44.

Fisher, J.A. and Monahan, T. (2008), "Tracking the social dimensions of RFID systems in hospitals", International Journal of Medical Informatics, Vol. 77, pp. 176-183.

Francis, D. L., Prabhakar, S. and Sanderson, S.O. (2009), "A Quality Initiative to Decrease Pathology Specimen- Labeling Errors Using Radio Frequency Identificaiton in a High-Volume Endoscopy Center," The American Journal of Gastroenterology, Vol. 104 April, pp. 972-975.

Fredendall, L. D., Craig, J.B., Fowler, P.J. and Damali, U. (2009), "Barriers to Swift, Even Flow in the Internal Supply chain of Peroperative Surgical Services Department: A Case Study", Decision Sciences, Vol. 40 May, pp. 327-349.

Kannry, J., Emro, S., Blount, M. and Ebling, M. (2007), "Small-scale Testing of RFID in a Hospital Setting: RFID as Bed Trigger", American Medical Informatics Association (AMIA) 2007 Symposim, Chicago, pp. 384-388.

Kumar, S. and Bauer, K. (2009), "The business case for implementing electronic health records in primary care settings in the United States", Journal of Revenue and Pricing Management, Vol. 10, pp 113.

Kumar, S., Dieveney, E. and Dieveney, A. ( 2009), "Reverse logistic process control measures for the pharmaceutical industry supply chain", International Journal of Productivity and Performance Management, Vol. 58 No. 2, pp. 188-204.

Kumar, S. and Kwong, A. (2011), "Six Sigma Tools in Integrating Internal Operations of a Retail Pharmacy - a Case Study”, Technology and Healthcare Journal, Vol. 19 No. 2, pp. 115-133.

Kumar, S., Livermont, G. and Mckewan, G. (2010), "Stage Implementation of RFID in Hospitals", Technology and HealthCare Journal, Vol. 18 No. 1, pp. 31-46.

Kumar, S. and Mckewan, G. (2011), “A Six Sigma DMAIC Quality Study for Expanded Role of Nurse Practitioners in the U.S. for Health Care During and Post Hospitalization, Journal of Home Health Care Management and Practice, Vol. 23 No. 4, pp. 271-282.

Kumar, S. and Sosinski, K.B. (2009), "Service delivery of care in children who have had strokes: Review of the initial diagnosis and ongoing treatments", Journal of Pediatric Neurology, Vol. 7 No. 3, pp. 231250. 
Kumar, S. and Sosnoski, M. (2009), "Using DMAIC Six Sigma to systematically improve shopfloor production quality and costs", International Journal of Productivity and Performance Mangement, Vol. 58, pp. 254-273.

Kumar, S., Swanson, E. and Tran, T. (2009), "RFID in the healthcare supply chain: usage and application", International Journal of Healthcare Quality Assurance, Vol. 22, pp. 67-81.

Kumar, S. and Steinebach, M. (2006), "Eliminating US hospital medical errors", International Journal of Healthcare Quality Assurance, Vol. 21, pp. 444-471.

Lanham, B. and Maxson-Cooper, P. (2003), "Is six sigma the answer for nursing to reduce medical errors?”, Nursing Economics, Vol. 21 No. 1, pp. 39-41.

Lavine, G. (2008), "RFID technology may improve contrast agent safety", American Journal of HealthSystem Pharmacy, Vol. 65 August 1, pp. 1400-1403.

Law, Averill (2007), Simulation Modeling and Analysis, $4^{\text {th }}$ Edition, McGraw-Hill Publishers, Boston.

Lin, C.-C., Lin, P.-Y, Lu, P.-K., Hsieh, G.-Y, Lee, W.-L, and Lee, R.-G. (2008), "A Healthcare Integration System for Disease Assessment and Safety Monitoring of Dementia Patients", IEEE Transactions on Information technology in Biomedicine, Vol. 12, pp. 579-586.

Marjamma, R. A., Torkki, P.M., Hirvensalo, E.J. and Kirvela, O.A. (2009), "What is the best workflow for an operating room? A simulation study of five scenarios", Health Care Management Science, Vol. 12, pp. 142-146.

Martini, C.R. (2008), "Brothers in Arms”, Health Management Technology, September, pp. 39-40.

Pexton, C. (2005), "One piece of the patient safety puzzle: Advantages of the six sigma approach", Patient Safety and Quality Healthcare, available at: http://www.psqh.com/janfeb05/sixsigma.html.

Pyzdek, T. and Keller, P. (2010), The Six Sigma Handbook, $3^{\text {rd }}$ Ed., McGraw Hill Publishers New York. Smith-Daniels, V. (2009), "In This Issue", Decision Sciences, Vol. 40, pp. 191-196.

Sun, P.R., Wang, B.H. and Wu, F. (2008), "A New Method to Guard Inpatient Medication Safety by the Implementation of RFID”, Journal of Medical Systems, Vol. 32, pp. 327-332.

Taner, M.T., Sezen, B. and Antony, J. (2007), "An Overview of Six Sigma Applications in Healthcare Industry", International Journal of Health Care Quality Assurance, Vol. 20, No. 4, pp. 329-340.

Thompson, C.A. (2004), "Radio frequency tags for identifying legitimate drug products discussed by tech Industry", American Journal of Health-System Pharmacy, Vol. 61 July 15, pp. 1430-1431.

Tu, Y.-J., Zhou, W., and Piramuthu, S.(2009), "Identifying RFID-embedded objects in pervasive healthcare applications," Decision Support Systems, Vol. 46, pp. 586-593.

Tzeng, S.-F., Chen, W., -H, and Pai, F,-Y. (2008), "Evaluating the business value of RFID: Evidence from five case studies," International Journal of Production Economics, Vol. 112, pp. 601-613. 
VanBerkel, P.T. and Blake, J.T. (2007), "A comprehensive simulation for wait time reduction and capacity planning applied in general surgery", Health Care Management Science, Vol. 10, pp. 373-385.

Whitehouse, U.S. (2011). http://www.whitehouse.gov/omb/assets/omb/fedreg/tort_claims.pdf (accessed August 31.2011)

(C) Emerald Group Publishing Limited

This is a pre-print of a paper and is subject to change before publication. This pre-print is made available with the understanding that it will not be reproduced or stored in a retrieval system without the permission of Emerald Group Publishing Limited. 
Table 1. Specific RFID Implementation Costs

\begin{tabular}{|c|c|c|c|}
\hline Item & Cost /item ${ }^{1}$ & \# of Items Needed ${ }^{2}$ & Total Estimated Cost \\
\hline Passive RFID Tags - Patients & $\$ .10$ & $8,000 /$ year & $\$ 800.00$ \\
\hline Passive RFID Tags - Employees & $\$ .10$ & 2,500 & $\$ 250.00$ \\
\hline Passive RFID Tags - Equipment & $\$ .10$ & 18,300 & $\$ 1,830$ \\
\hline Passive RFID Tags - Ind. Supplies/Drugs & $\$ .10$ & $80,000 /$ year & $\$ 8,000.00$ \\
\hline $\begin{array}{l}\text { Separate RFID Tag Readers (1 per op } \\
\text { room) }\end{array}$ & $\$ 2,200.00$ & 5 & $\$ 11,000.00$ \\
\hline Software & $\$ 35,000.00$ & 1 & $\$ 35,000.00$ \\
\hline Total $^{3}$ & & & $\$ 56,880.00$ \\
\hline
\end{tabular}

Notes:

1. Interview and correspondence with Chris Wassel, RFID Program Manager of the RFID Center of Excellence, Penn State Erie, The Behrend College, in Erie, PA.

2. Estimates based on interviews with hospital personnel.

3. Of the total $\$ 56,880$, part of that $(\$ 48,080)$ is a one-time cost while the remainder $(\$ 8,800)$ is an annual one. There will some annual costs under employees as well, as additional people are hired. 


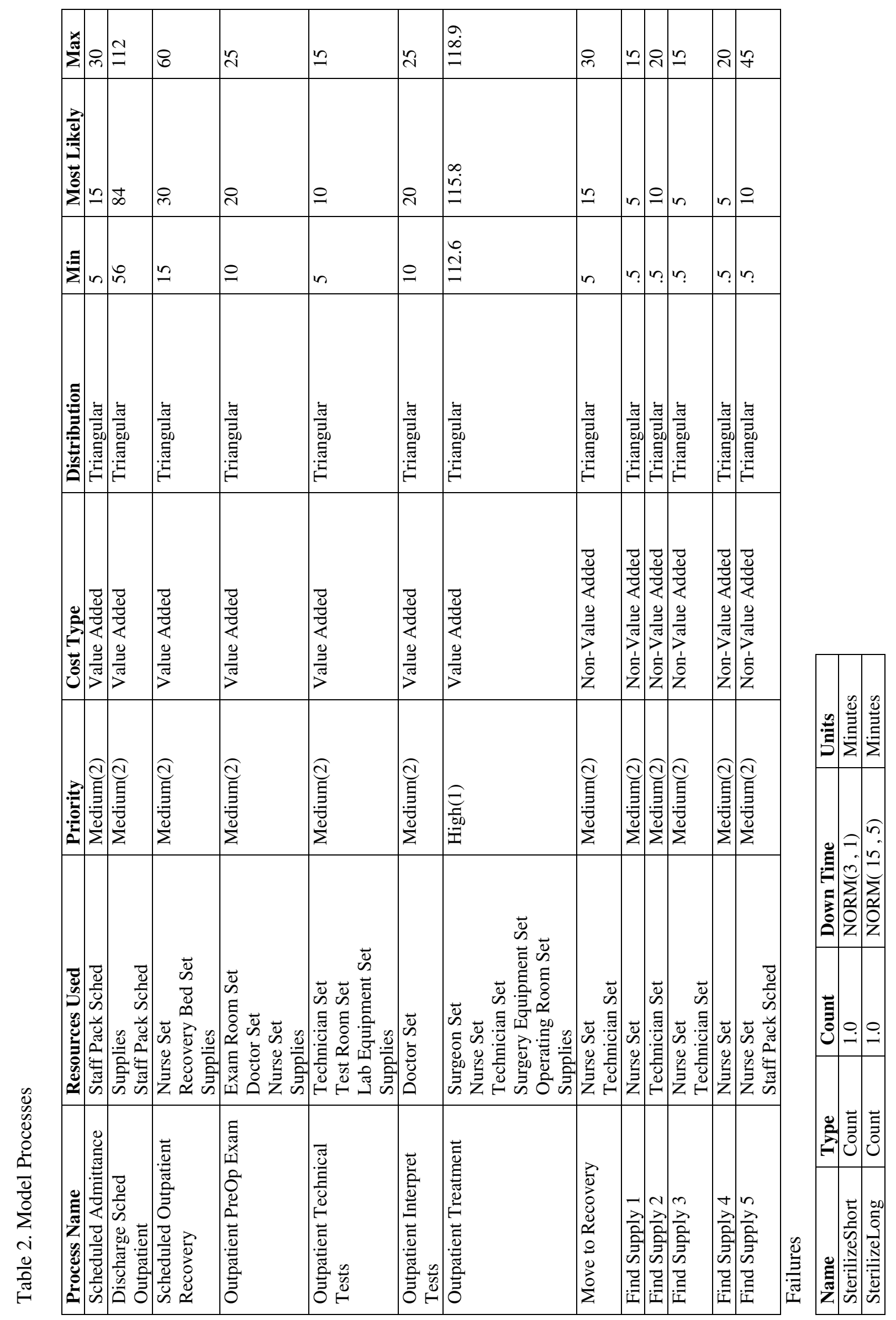

(c) Emerald Group Publishing Limited

This is a pre-print of a paper and is subject to change before publication. This pre-print is made available with the understanding that it will not be reproduced or stored in a retrieval system without the permission of Emerald Group Publishing Limited. 
Table 3. Resource Costs

\begin{tabular}{|c|c|c|c|c|}
\hline Name & Capacity & Busy/hr & Idle/hr & Per use \\
\hline Doctor Pack Sched & 12 & \begin{tabular}{|l|}
0.0 \\
\end{tabular} & 0.0 & 2071 \\
\hline Nurse Pack Sched & 22 & 34 & 34 & 0.0 \\
\hline Staff Pack Sched & 5 & 15.5 & 15.5 & 0.0 \\
\hline Equip Pack Sched & 5 & 0.0 & 0.0 & 784.42 \\
\hline Sched Technical Staff & 7 & 22 & 22 & 0.0 \\
\hline Lab Equip Sched & 2 & 0.0 & 0.0 & 784.42 \\
\hline Operating Room Pack & 5 & 0.0 & 0.0 & 784.42 \\
\hline Exam Room Pack & 6 & 0.0 & 0.0 & 784.42 \\
\hline Test Room Pack & 2 & 0.0 & 0.0 & 784.42 \\
\hline Recovery Bed Pack & 10 & 0.0 & 0.0 & 784.42 \\
\hline Supply Pack & 1 & 0.0 & 0.0 & 784.42 \\
\hline Doctor 1 & 1 & 0.0 & 0.0 & 100 \\
\hline Doctor 2 & 1 & 0.0 & 0.0 & 100 \\
\hline Doctor 3 & 1 & 0.0 & 0.0 & 100 \\
\hline Doctor 4 & 1 & 0.0 & 0.0 & 100 \\
\hline Doctor 5 & 1 & 0.0 & 0.0 & 100 \\
\hline Doctor 6 & 1 & 0.0 & 0.0 & 100 \\
\hline Doctor 7 & 1 & 0.0 & 0.0 & 100 \\
\hline Doctor 8 & 1 & 0.0 & 0.0 & 100 \\
\hline Doctor 9 & 1 & 0.0 & 0.0 & 100 \\
\hline Doctor 10 & 1 & 0.0 & 0.0 & 100 \\
\hline Doctor 11 & 1 & 0.0 & 0.0 & 100 \\
\hline Doctor 12 & 1 & 0.0 & 0.0 & 100 \\
\hline Nurse 1 & 1 & 34 & 34 & 100 \\
\hline Nurse 2 & 1 & 34 & 34 & 0.0 \\
\hline Nurse 3 & 1 & 34 & 34 & 0.0 \\
\hline Nurse 4 & 1 & 34 & 34 & 0.0 \\
\hline Nurse 5 & 1 & 34 & 34 & 0.0 \\
\hline Nurse 6 & 1 & 34 & 34 & 0.0 \\
\hline Nurse 7 & 1 & 34 & 34 & 0.0 \\
\hline Nurse 8 & 1 & 34 & 34 & 0.0 \\
\hline Nurse 9 & 1 & 34 & 34 & 0.0 \\
\hline Nurse 10 & 1 & 34 & 34 & 0.0 \\
\hline Nurse 11 & 1 & 34 & 34 & 0.0 \\
\hline Nurse 12 & 1 & 34 & 34 & 0.0 \\
\hline Nurse 13 & 1 & 34 & 34 & 0.0 \\
\hline Nurse 14 & 1 & 34 & 34 & 0.0 \\
\hline Nurse 15 & 1 & 34 & 34 & 0.0 \\
\hline Nurse 16 & 1 & 34 & 34 & 0.0 \\
\hline Nurse 17 & 1 & 34 & 34 & 0.0 \\
\hline Nurse 18 & 1 & 34 & 34 & 0.0 \\
\hline Nurse 19 & 1 & 34 & 34 & 0.0 \\
\hline Nurse 20 & 1 & 34 & 34 & 0.0 \\
\hline Nurse 21 & 1 & 34 & 34 & 0.0 \\
\hline Nurse 22 & 1 & 34 & 34 & 0.0 \\
\hline Surgery Equip 1 & 1 & 0.0 & 0.0 & 784.42 \\
\hline Surgery Equip 2 & 1 & 0.0 & 0.0 & 784.42 \\
\hline Surgery Equip 3 & 1 & 0.0 & 0.0 & 784.42 \\
\hline Surgery Equip 4 & 1 & 0.0 & 0.0 & 784.42 \\
\hline Surgery Equip 5 & 1 & 0.0 & 0.0 & 784.42 \\
\hline
\end{tabular}

(c) Emerald Group Publishing Limited

This is a pre-print of a paper and is subject to change before publication. This pre-print is made available with the understanding that it will not be reproduced or stored in a retrieval system without the permission of Emerald Group Publishing Limited. 
Table 3. Resource Costs (continued)

\begin{tabular}{|l|l|l|l|l|}
\hline Name & Capacity & Busy/hr & Idle/hr & Per use \\
\hline Technician 1 & 1 & 22 & 22 & 0.0 \\
\hline Technician 2 & 1 & 22 & 22 & 0.0 \\
\hline Technician 3 & 1 & 22 & 22 & 0.0 \\
\hline Technician 4 & 1 & 22 & 22 & 0.0 \\
\hline Technician 5 & 1 & 22 & 22 & 0.0 \\
\hline Lab Equip 1 & 1 & 0.0 & 0 & 784.42 \\
\hline Lab Equip 2 & 1 & 0.0 & 0.0 & 784.42 \\
\hline Operating Room 1 & 1 & 0.0 & 0.0 & 784.42 \\
\hline Operating Room 2 & 1 & 0.0 & 0.0 & 784.42 \\
\hline Operating Room 3 & 1 & 0.0 & 0.0 & 784.42 \\
\hline Operating Room 4 & 1 & 0.0 & 0.0 & 784.42 \\
\hline Operating Room 5 & 1 & 0.0 & 0.0 & 784.42 \\
\hline Operating Room 6 & 1 & 0.0 & 0.0 & 784.42 \\
\hline Operating Room 7 & 1 & 0.0 & 0.0 & 784.42 \\
\hline Operating Room 8 & 1 & 0.0 & 0.0 & 784.42 \\
\hline Operating Room 9 & 1 & 0.0 & 0.0 & 784.42 \\
\hline Operating Room 10 & 1 & 0.0 & 0.0 & 784.42 \\
\hline Exam Room 1 & 1 & 0.0 & 0.0 & 784.42 \\
\hline Exam Room 2 & 1 & 0.0 & 0.0 & 784.42 \\
\hline Exam Room 3 & 1 & 0.0 & 0.0 & 784.42 \\
\hline Exam Room 4 & 1 & 0.0 & 0.0 & 784.42 \\
\hline Exam Room 5 & 1 & 0.0 & 0.0 & 784.42 \\
\hline Exam Room 6 & 1 & 0.0 & 0.0 & 784.42 \\
\hline Recovery Bed 1 & 1 & 0.0 & 0.0 & 784.42 \\
\hline Recovery Bed 2 & 1 & 0.0 & 0.0 & 784.42 \\
\hline Recovery Bed 3 & 1 & 0.0 & 0.0 & 784.42 \\
\hline Recovery Bed 4 & 1 & 0.0 & 0.0 & 784.42 \\
\hline Recovery Bed 5 & 1 & 0.0 & 0.0 & 784.42 \\
\hline Recovery Bed 6 & 1 & 0.0 & 0.0 & 784.42 \\
\hline Recovery Bed 7 & 1 & 0.0 & 0.0 & 784.42 \\
\hline Recovery Bed 8 & 1 & 0.0 & 0.0 & 784.42 \\
\hline Recovery Bed 9 & 1 & 0.0 & 0.0 & 784.42 \\
\hline Recovery Bed 10 & 1 & 0.0 & 0.0 & 784.42 \\
\hline Technician 6 & 1 & 22 & 22 & 0.0 \\
\hline Technician 7 & 1 & 22 & 22 & 0.0 \\
\hline Supplies & Infinite & 0.0 & 0.0 & 784.42 \\
\hline Test Room 1 & 1 & 0.0 & 0.0 & 784.42 \\
\hline Test Room 2 & 1 & 0.0 & 0.0 & 784.42 \\
\hline surgeon 1 & 1 & 0.0 & 0.0 & 2071 \\
\hline surgeon 2 & 1 & 0.0 & 0.0 & 2071 \\
\hline surgeon 3 & 1 & 0.0 & 0.0 & 2071 \\
\hline surgeon 4 & 1 & 0.0 & 0.0 & 2071 \\
\hline surgeon 5 & 1 & 0.0 & 0.0 & 2071 \\
\hline surgeon 6 & 1 & 0.0 & 0.0 & 2071 \\
\hline surgeon 7 & 1 & 0.0 & 0.0 & 2071 \\
\hline surgeon 8 & 0.0 & 0.0 & 2071 \\
\hline surgeon 9 & 0.0 & 0.0 & 2071 \\
\hline surgeon 10 & 1 & 0.0 & 0.0 & 2071 \\
\hline surgeon 11 & 0.0 & 0.0 & 2071 \\
\hline surgeon 12 & & & 2071 \\
\hline
\end{tabular}


Table 4. Model Results File (per 5 day week)

\begin{tabular}{|l|c|c|c|}
\hline \multicolumn{1}{|c|}{ Description } & Without RFID & With RFID & Savings/week \\
\hline Total Costs & $\$ 865,489$ & $\$ 828,326$ & $\$ 37,163$ \\
\hline Average Cost Per Patient & $\$ 5,910$ & $\$ 5,612$ & $\$ 298$ \\
\hline Average Time Per Patient & 6.4 hours & 5.3 hours & 1.1 hours \\
\hline
\end{tabular}

Table 5. Costs and Times (per 5 day week)

\begin{tabular}{|l|c|c|c|}
\hline \multicolumn{1}{|c|}{ Description } & Without RFID & With RFID & Savings/week \\
\hline Total Non-value Added Costs & $\$ 4,242$ & $\$ 835$ & $\$ 3,407$ \\
\hline Total Value Added Costs & $\$ 647,954$ & $\$ 611,715$ & $\$ 36,239$ \\
\hline Total Busy Costs* & $\$ 12,482$ & $\$ 10,002$ & $\$ 2,480$ \\
\hline Total Idle Costs & $\$ 213,293$ & $\$ 215,776$ & $\$ 2,483)$ \\
\hline Total Usage Costs* & $\$ 639,714$ & $\$ 602,547$ & $\$ 37,167$ \\
\hline & & & \\
\hline Per Patient Times (hours) & & & 0.0832 \\
\hline Value Added Time & 2.5804 & 2.4972 & 0.4505 \\
\hline Non-value Added Time & .5871 & .1366 & 0.0060314 \\
\hline Wait Time & .01945503 & .01342363 & 1.0796 \\
\hline \multicolumn{1}{|c|}{ Total Time } & 6.3739 & 5.2943 & \\
\hline
\end{tabular}

*These two costs equal the sum of Value and Non-value added costs. 


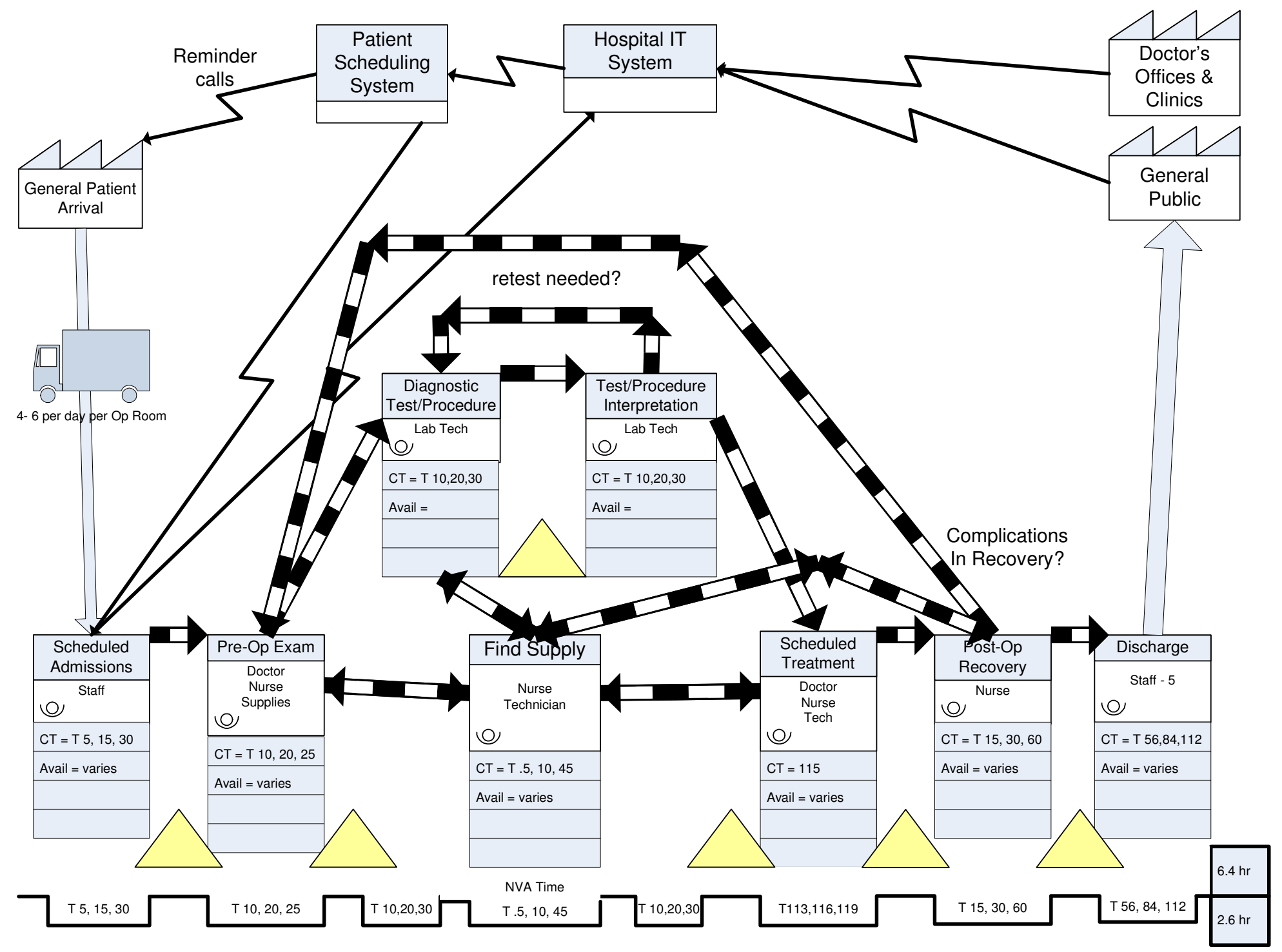

Figure 1. Value Stream Map without RFID

(c) Emerald Group Publishing Limited

This is a pre-print of a paper and is subject to change before publication. This pre-print is made available with the understanding that it will not be reproduced or stored in a retrieval system without the permission of Emerald Group Publishing Limited. 


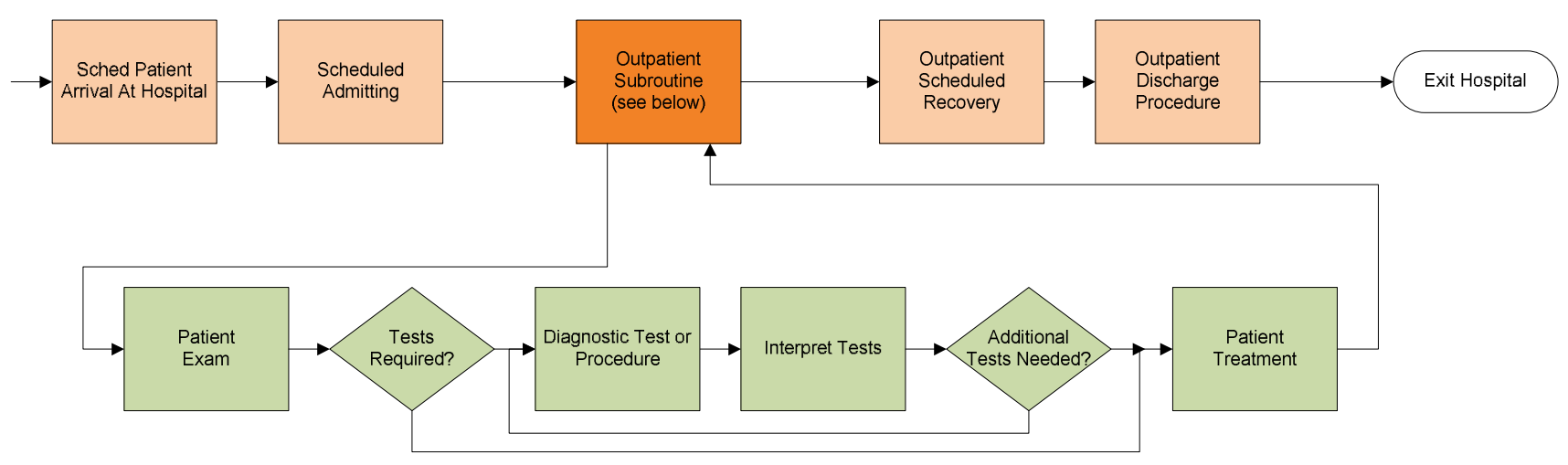

Figure 2. Outpatient Surgical Process Flow Map

(c) Emerald Group Publishing Limited

This is a pre-print of a paper and is subject to change before publication. This pre-print is made available with the understanding that it will not be reproduced or stored in a retrieval system without the permission of Emerald Group Publishing Limited. 


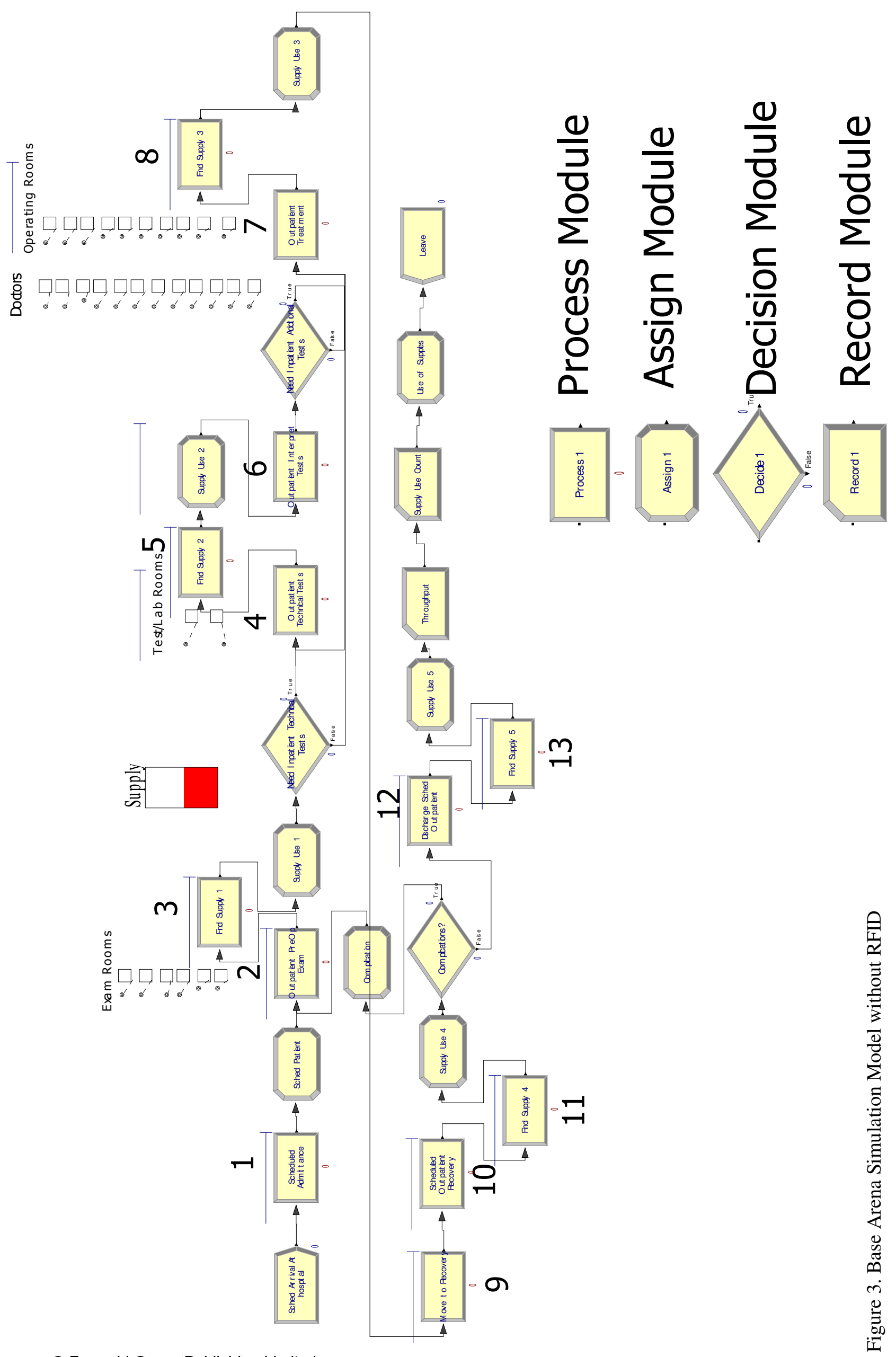

(c) Emerald Group Publishing Limited

This is a pre-print of a paper and is subject to change before publication. This pre-print is made available with the understanding that it will not be reproduced or stored in a retrieval system without the permission of Emerald Group Publishing Limited. 


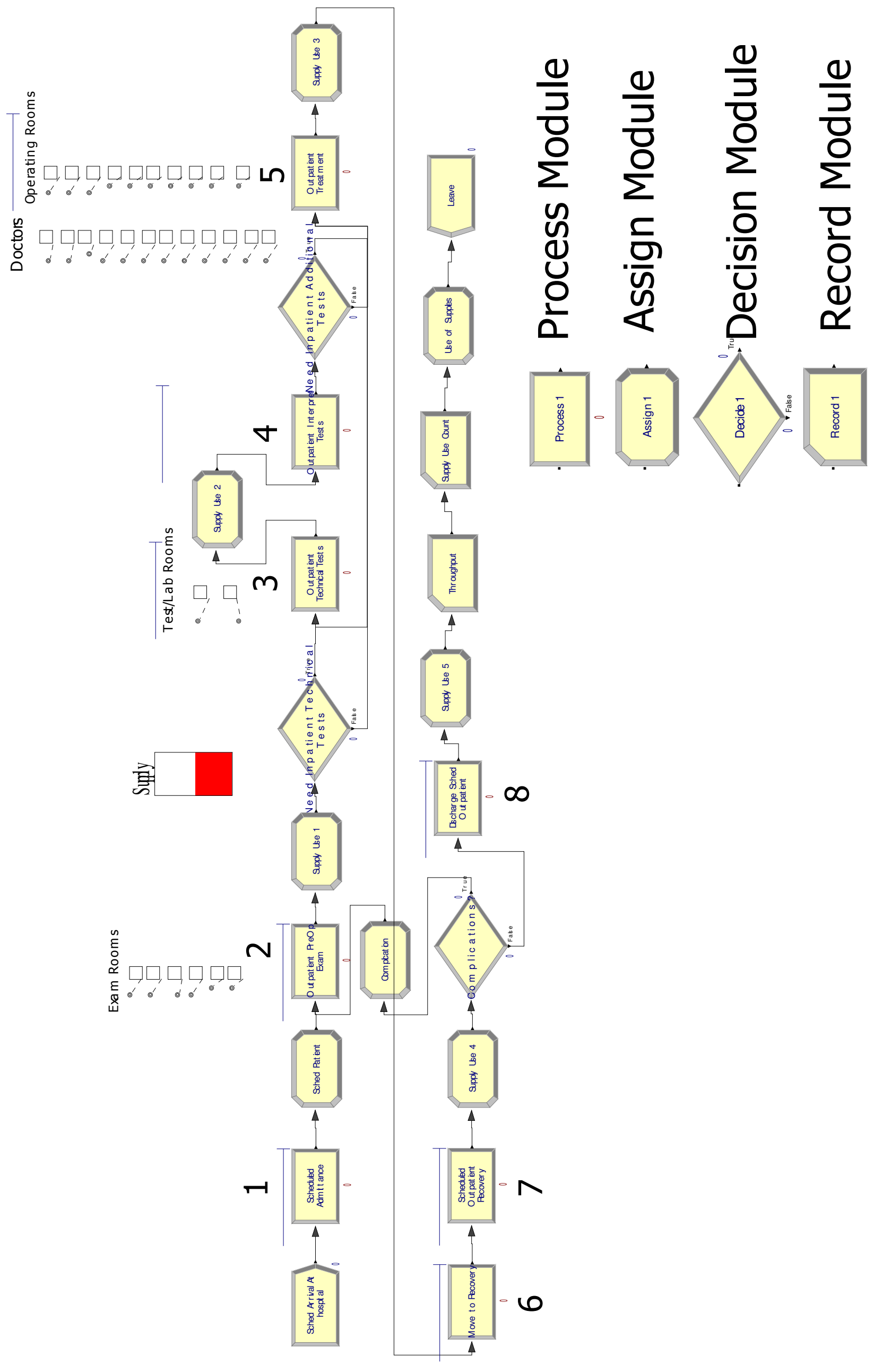



(C) Emerald Group Publishing Limited

This is a pre-print of a paper and is subject to change before publication. This pre-print is made available with the understanding that it will not be reproduced or stored in a retrieval system without the permission of Emerald Group Publishing Limited. 


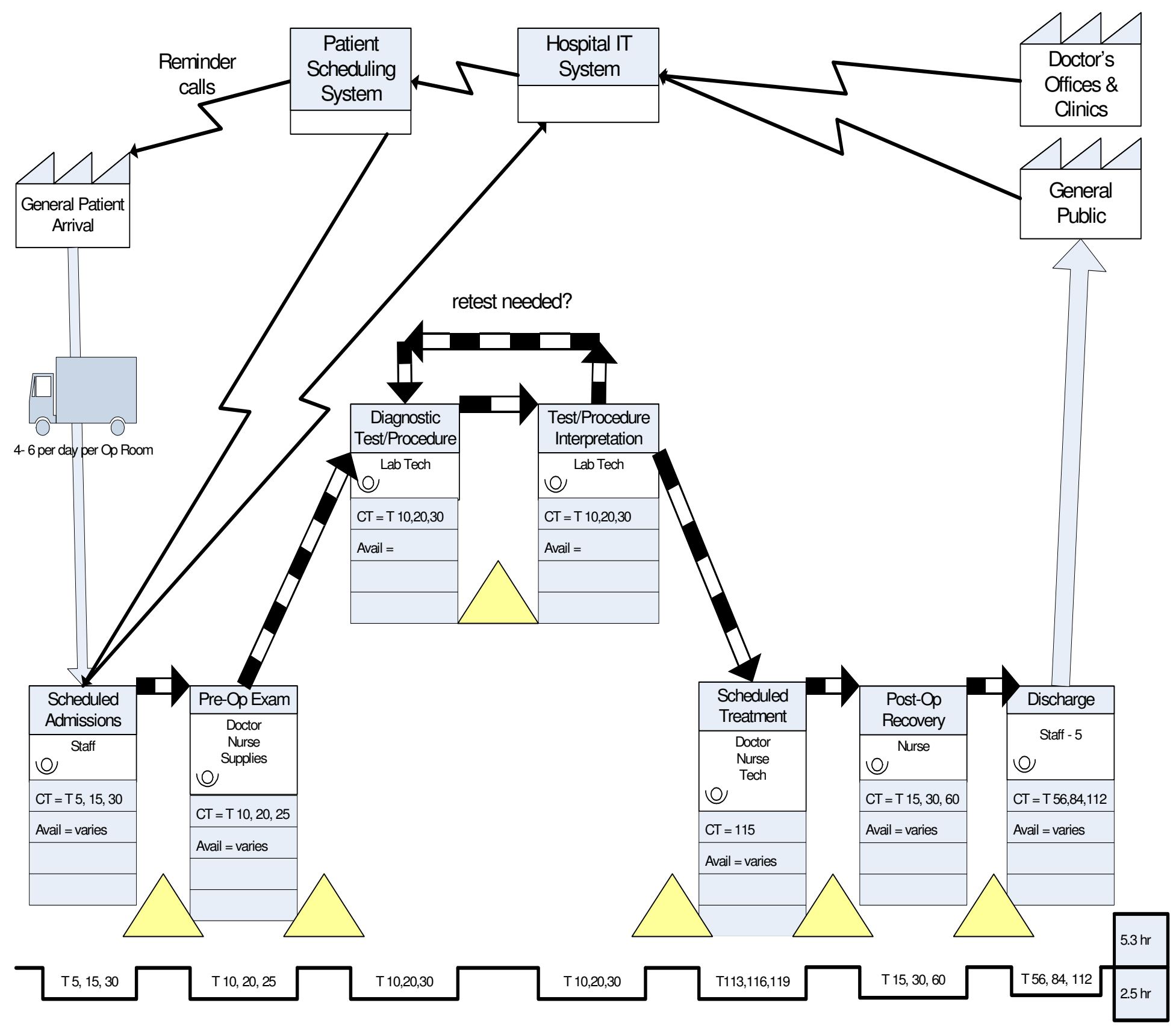

Figure 5. Value Stream Map with RFID

(c) Emerald Group Publishing Limited

This is a pre-print of a paper and is subject to change before publication. This pre-print is made available with the understanding that it will not be reproduced or stored in a retrieval system without the permission of Emerald Group Publishing Limited. 


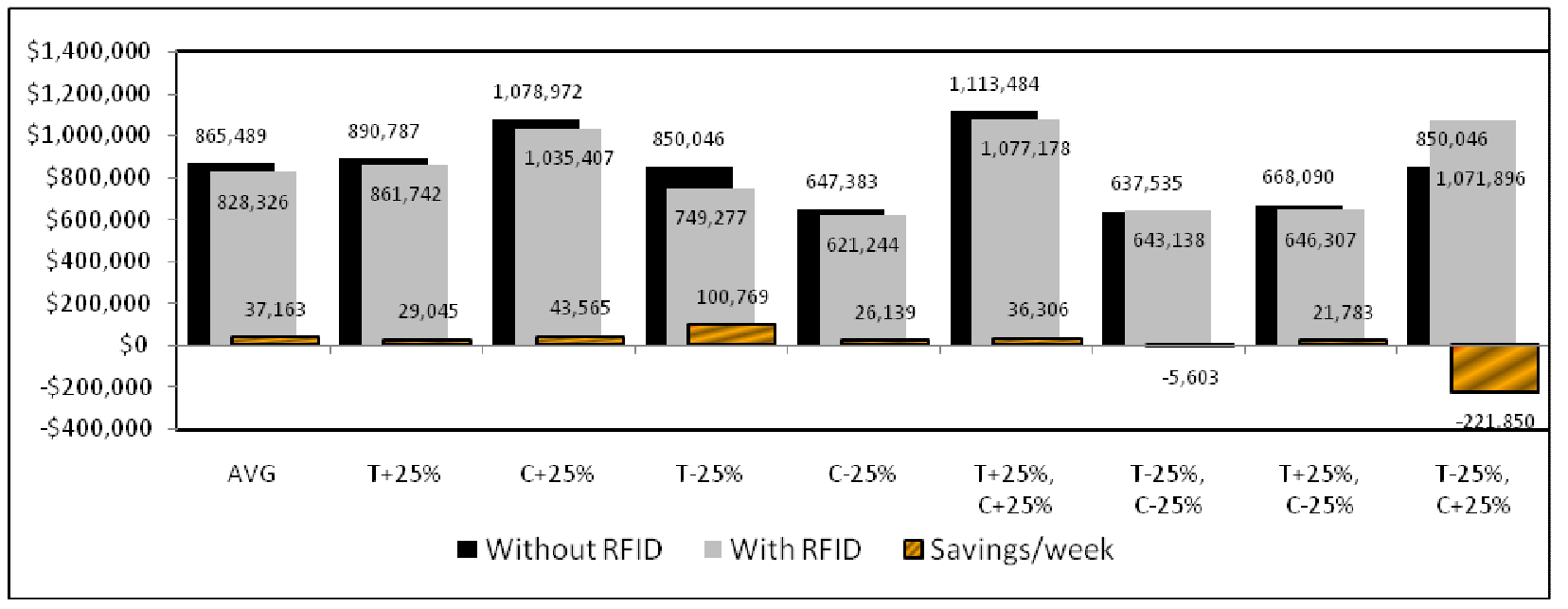

Figure 6. Sensitivity of Total Costs within $\pm 25 \%$ range of costs $(C)$ and time (T)

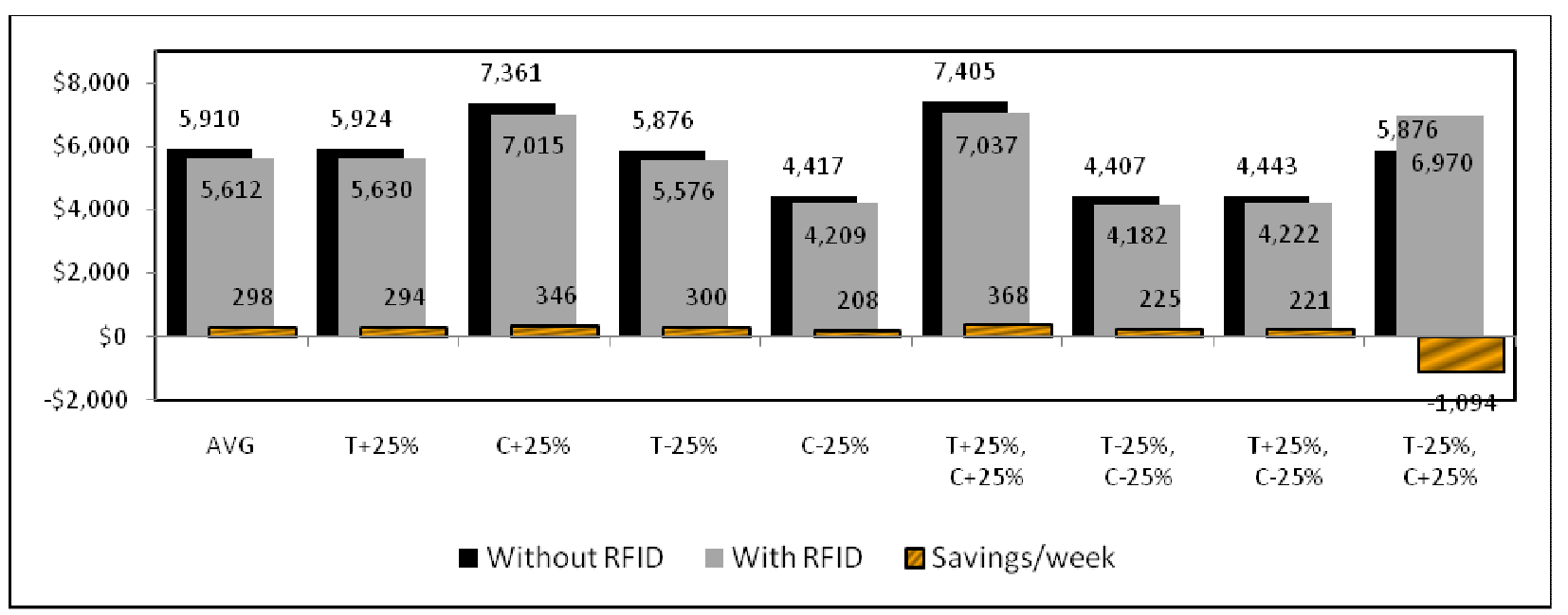

Figure 7. Sensitivity of Average Cost Per Patient within $\pm 25 \%$ range of costs (C) and time (T)

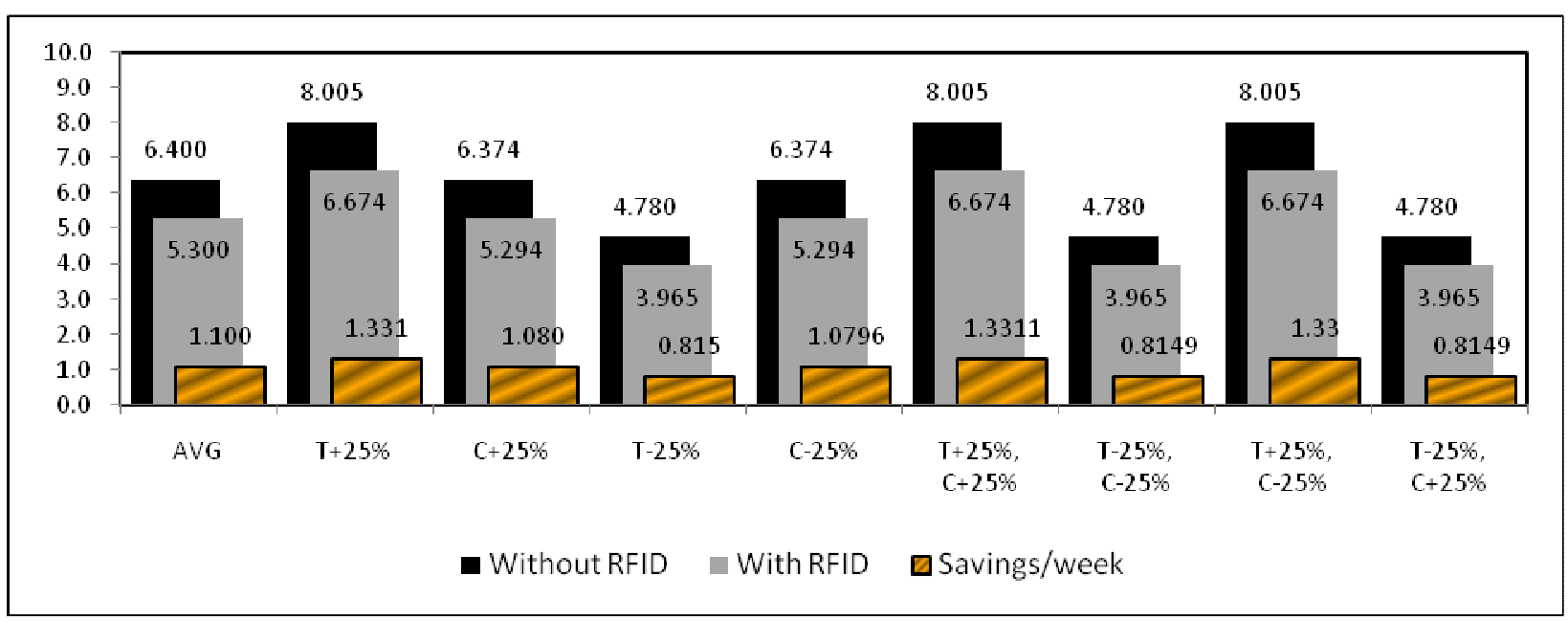

Figure 8. Sensitivity of Average Time Per Patient (hours) within $\pm 25 \%$ range of costs (C) and time (T)

(c) Emerald Group Publishing Limited

This is a pre-print of a paper and is subject to change before publication. This pre-print is made available with the understanding that it will not be reproduced or stored in a retrieval system without the permission of Emerald Group Publishing Limited. 

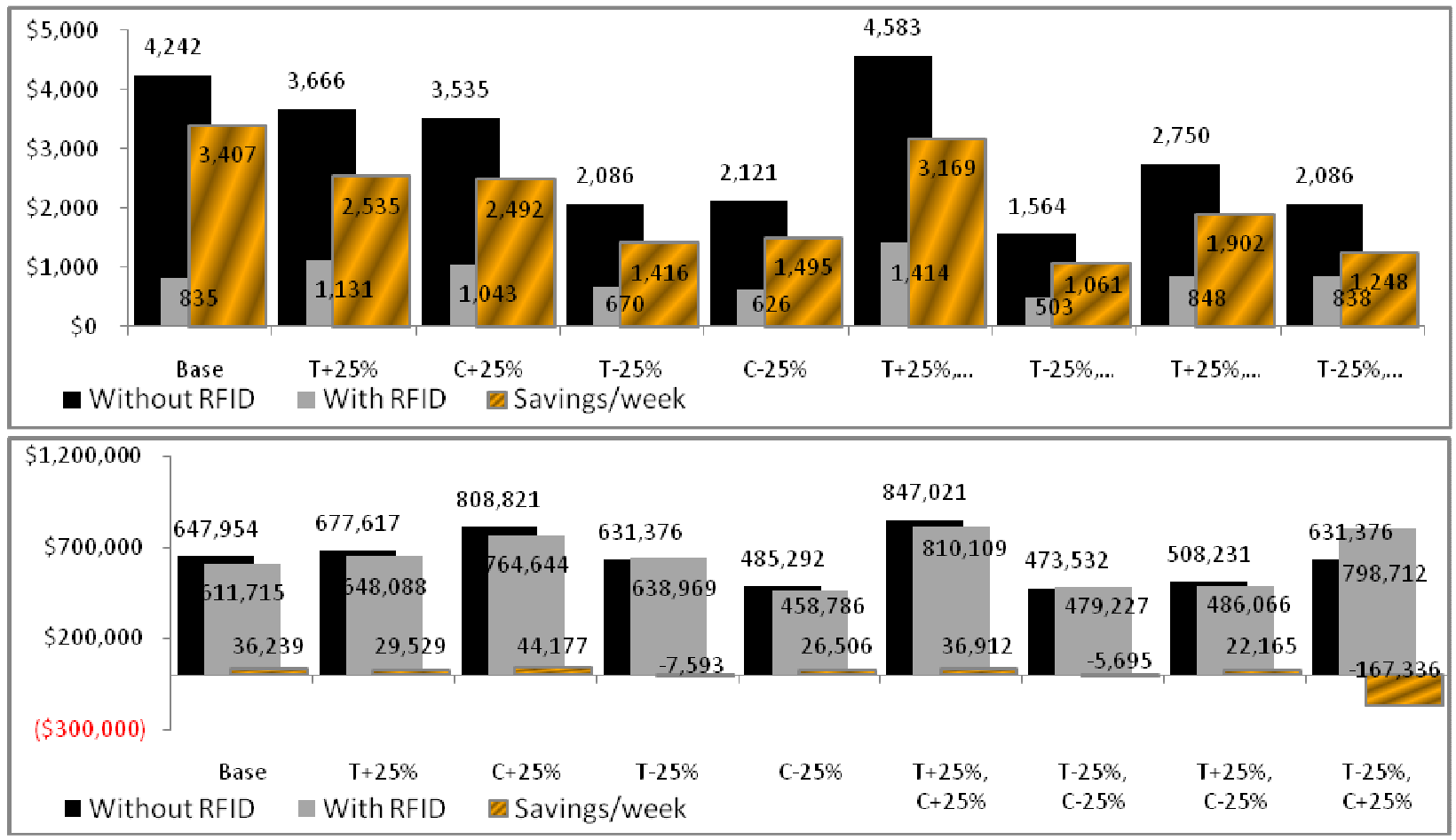

Figure 9. Sensitivity of Total Non-value Added Costs (top) and Total Value Added Costs (bottom), within $\pm 25 \%$ range of costs $(\mathrm{C})$ and time $(\mathrm{T})$

(c) Emerald Group Publishing Limited

This is a pre-print of a paper and is subject to change before publication. This pre-print is made available with the understanding that it will not be reproduced or stored in a retrieval system without the permission of Emerald Group Publishing Limited. 

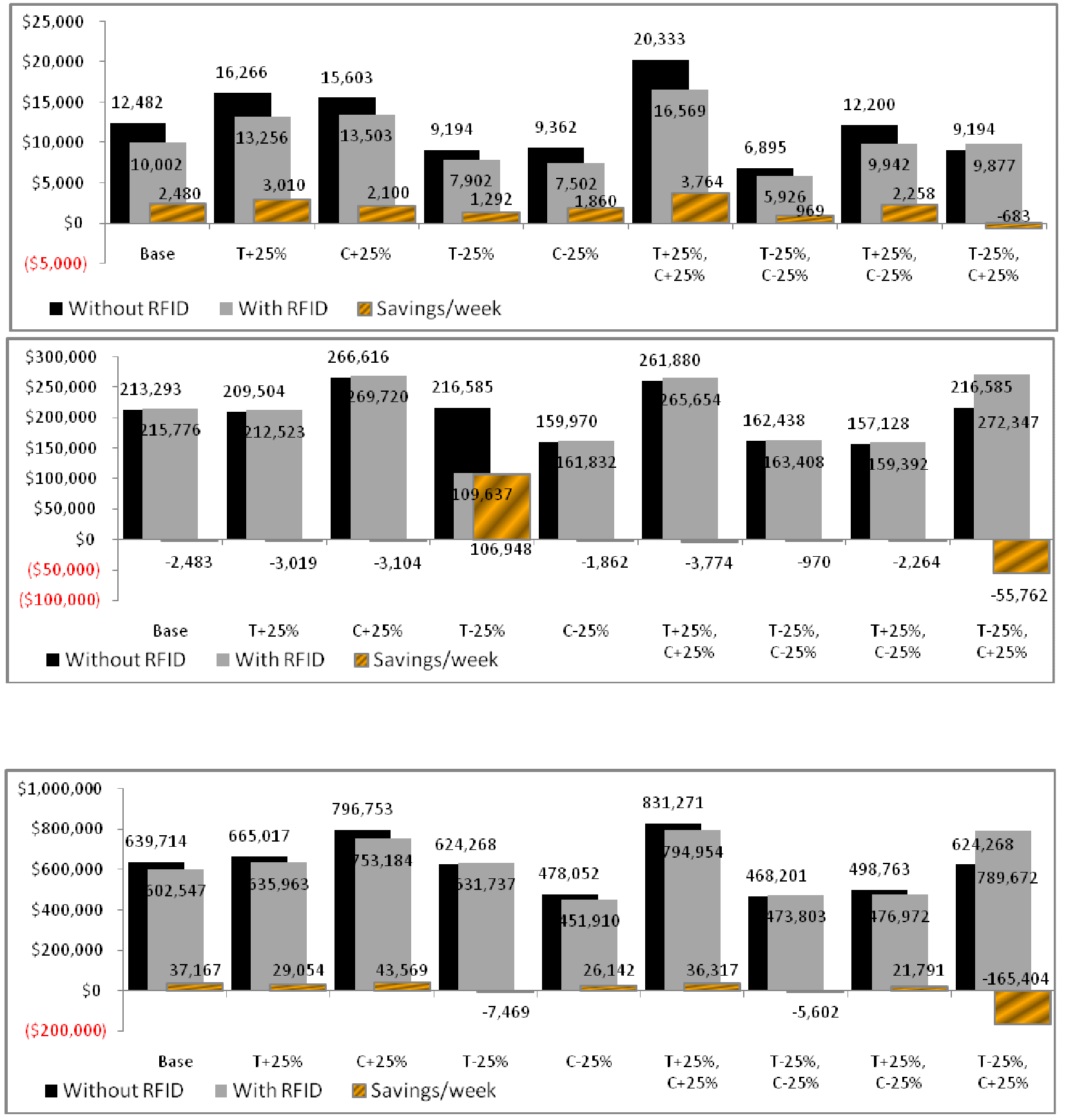

Figure 10. Sensitivity of Total Busy Costs (top), Total Idle Costs (middle) and Total Usage Costs (bottom), within $\pm 25 \%$ range of costs $(\mathrm{C})$ and time $(\mathrm{T})$

(c) Emerald Group Publishing Limited

This is a pre-print of a paper and is subject to change before publication. This pre-print is made available with the understanding that it will not be reproduced or stored in a retrieval system without the permission of Emerald Group Publishing Limited. 


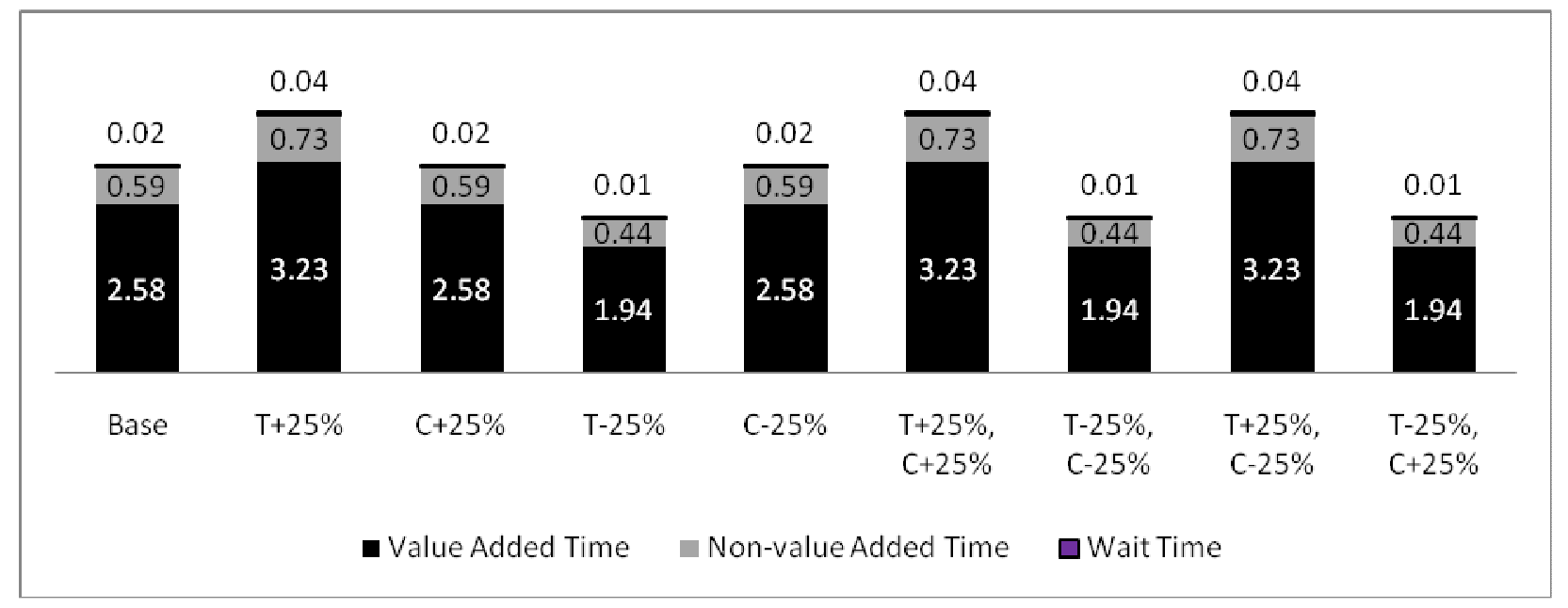

Figure 11. Sensitivity of Per Patient Times for Without RFID within $\pm 25 \%$ range of costs (C) and time (T)

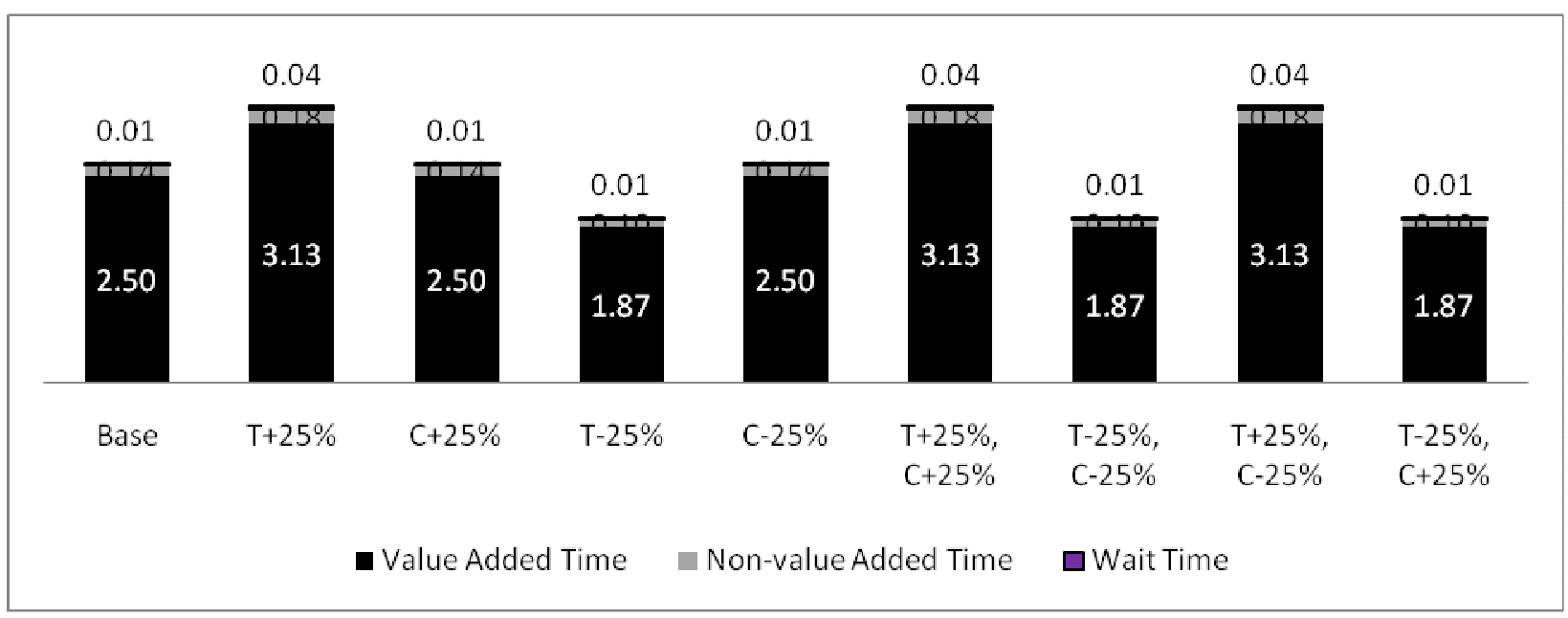

Figure 12. Sensitivity of Per Patient Times for With RFID within $\pm 25 \%$ range of costs (C) and time (T)

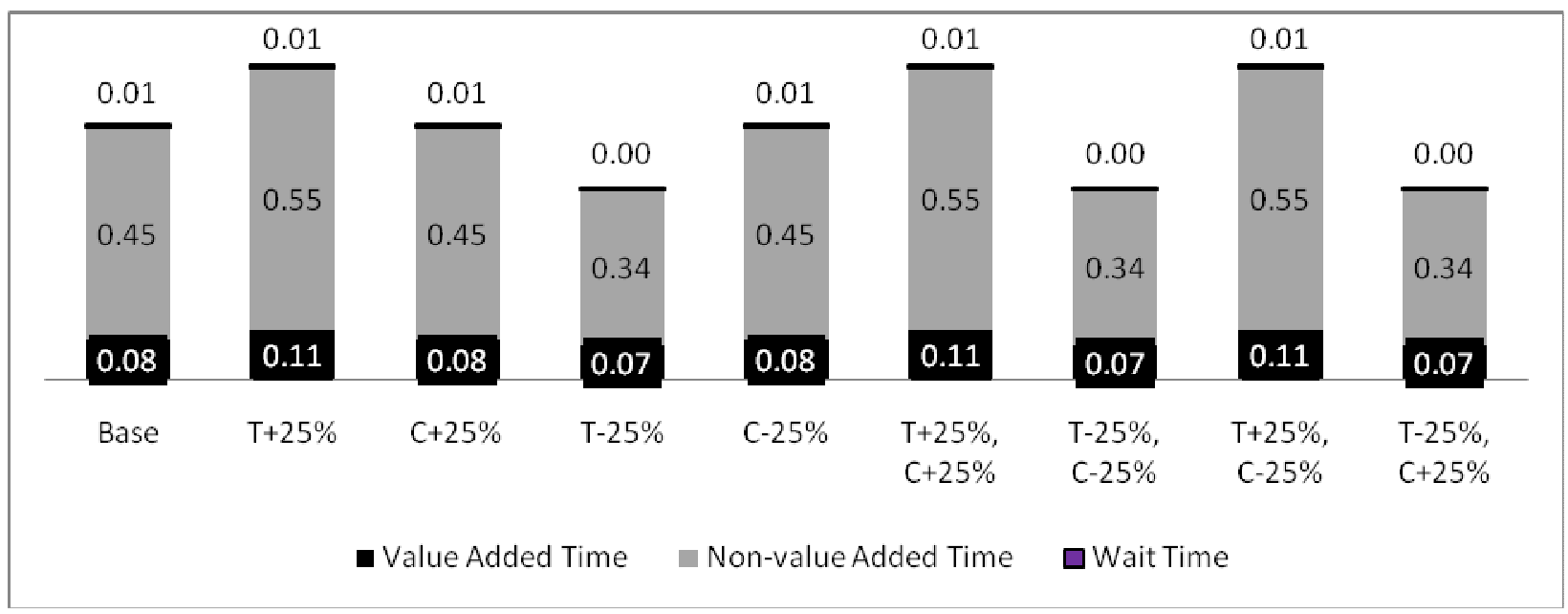

Figure 13. Sensitivity of Per Patient Times for Savings/Week within $\pm 25 \%$ range of costs (C) and time (T)

(c) Emerald Group Publishing Limited

This is a pre-print of a paper and is subject to change before publication. This pre-print is made available with the understanding that it will not be reproduced or stored in a retrieval system without the permission of Emerald Group Publishing Limited. 


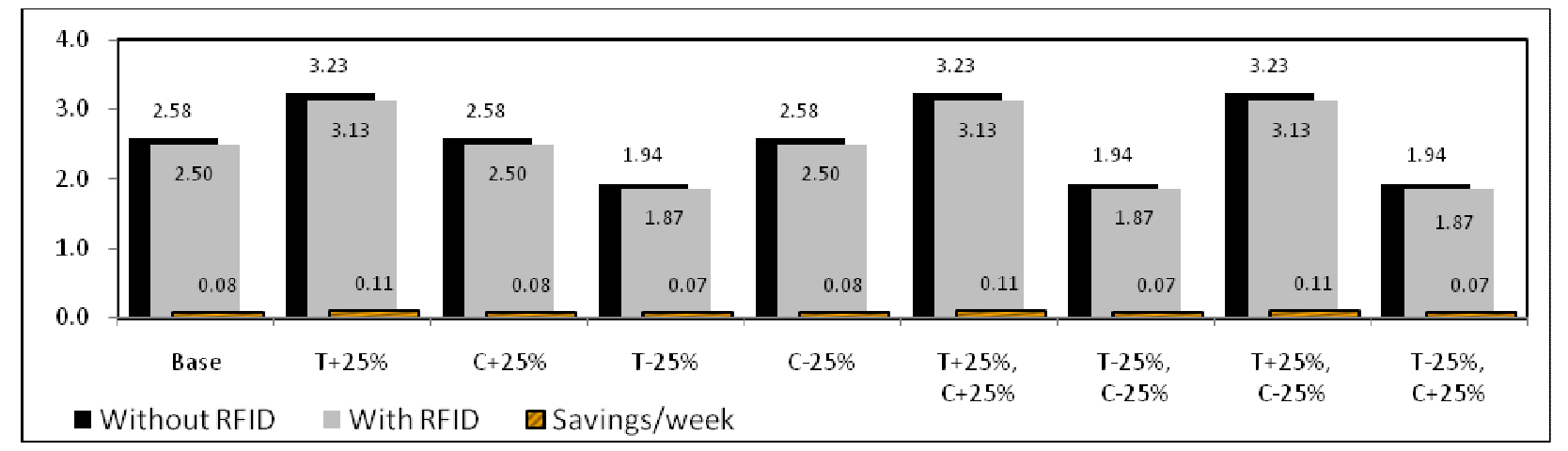

Figure 14. Sensitivity of Per Patient Times for Value Added Time within $\pm 25 \%$ range of costs (C) and time (T)

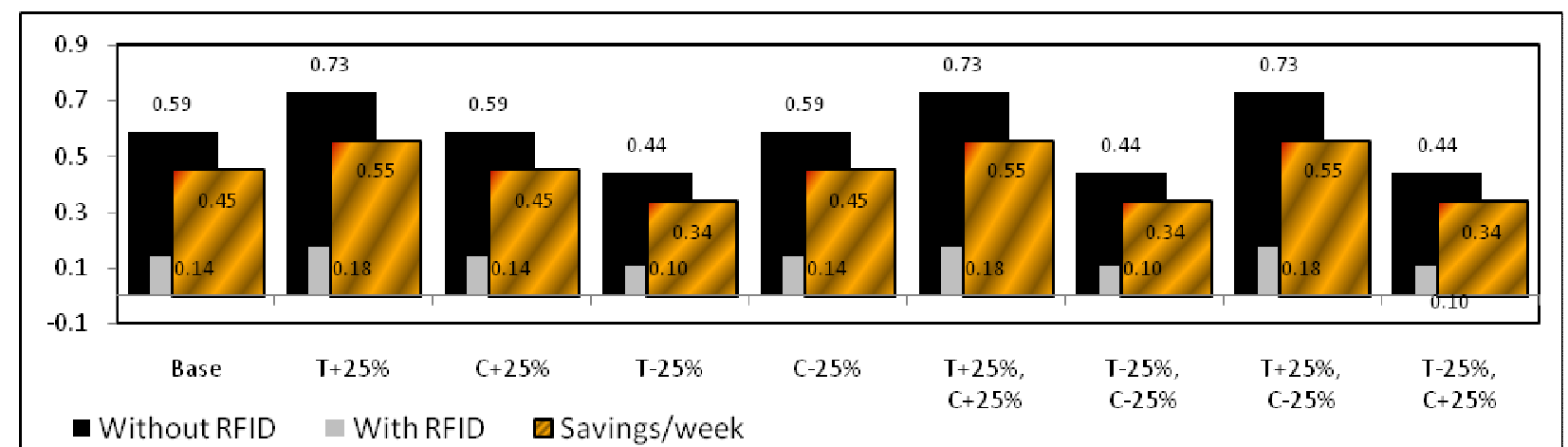

Figure 15. Sensitivity of Per Patient Times for Non-Value Added Time within $\pm 25 \%$ range of costs (C) and time (T)

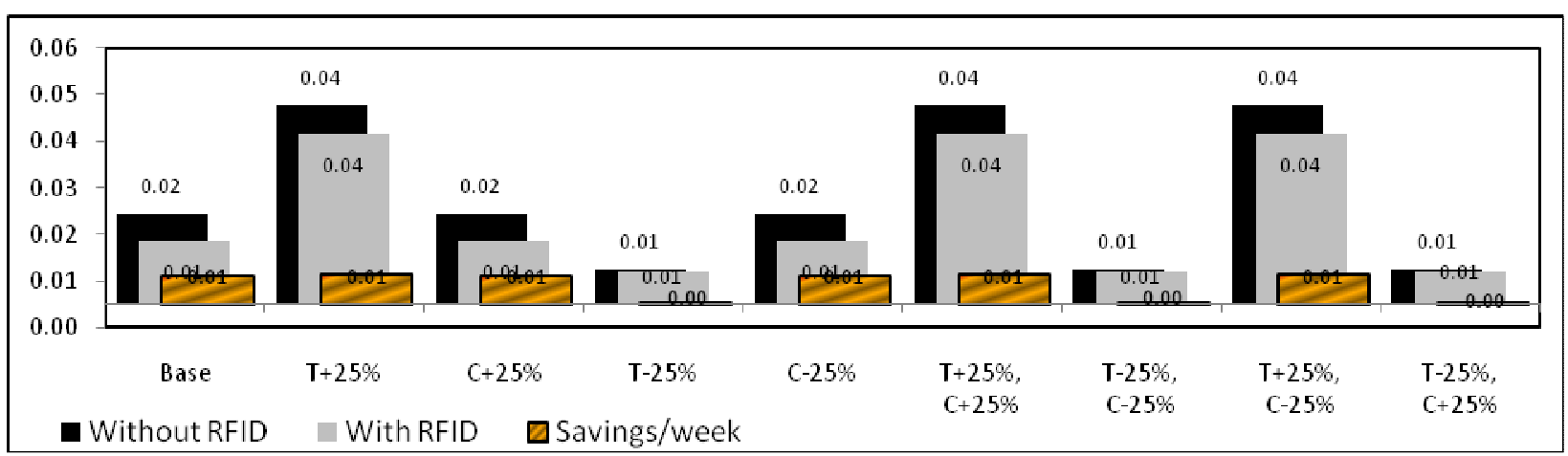

Figure 16. Sensitivity of Per Patient Times for Wait Time within $\pm 25 \%$ range of costs $(\mathrm{C})$ and time (T)

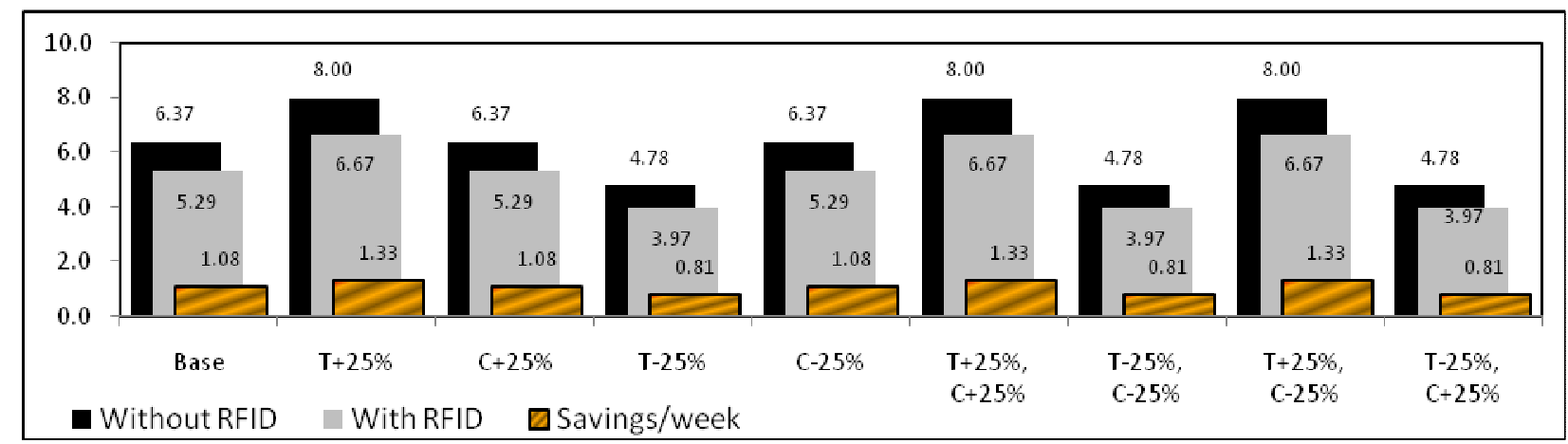

Figure 17. Sensitivity of Per Patient Times for Total Time within $\pm 25 \%$ range of costs $(C)$ and time (T)

(c) Emerald Group Publishing Limited

This is a pre-print of a paper and is subject to change before publication. This pre-print is made available with the understanding that it will not be reproduced or stored in a retrieval system without the permission of Emerald Group Publishing Limited. 